\title{
RESEARCH
}

\section{Many systems, one strategy: Acquiring ordinals in Dutch and English}

\author{
Caitlin Meyer ${ }^{1}$, Sjef Barbiers ${ }^{2}$ and Fred Weerman ${ }^{1}$ \\ 1 University of Amsterdam, NL \\ ${ }^{2}$ Leiden University, NL \\ Corresponding author: Caitlin Meyer (c.m.meyer@uva.nl)
}

This study compares ordinal acquisition in Dutch and English, and shows that both groups of learners acquire ordinals via a rule, rather than lexically. Our evidence comes from a Give-X type comprehension task (cf. Wynn 1992, Meyer et al. 2018, under review) which we administered to 70 Dutch L1 learners (2;08-4;11) and 35 learners of American English (3;3-5;3). The data not only offer a replication of the core findings in Meyer et al. (2018), showing that Dutch-speaking children acquire irregular forms (such as derde 'third') after they acquire regular synthetic forms (such as vierde 'fourth'), but also show that (i) children acquire irregular forms after analytic forms (e.g., boot zes 'boat six'), and (ii) the rule-based pattern that holds for Dutch also holds for English. We argue that children use the ordinal form to acquire its meaning, which implies that ordinals are acquired in a different way than cardinal numerals (which follow a slow, sequential pattern), and also what is typically described for derivation (which initially tends to follow a lexical pattern, i.e., one in which complex forms are stored as wholes before children learn they can be formed productively by means of a rule).

Keywords: ordinal numerals; L1 acquisition; morphology; Dutch; English; comprehension

\section{Introduction}

Children are somehow able to break down the endless stream of sounds they hear into pieces that fit into an intricate system of structure and meaning. This paper provides evidence that linguistic structure can be a useful and perhaps necessary tool in acquiring meaning and developing abstract concepts, even when the evidence in the input does not seem immediately obvious. More precisely, we argue that children use the morphosyntactic properties of ordinal numerals to acquire ordinal meaning, and that this strategy is not as straightforward as it might seem.

We build our argument, and the present study in general, on two previous studies on ordinal acquisition by Meyer, Barbiers \& Weerman (2018, under review). These studies shared two key findings that point in the direction of rule-based acquisition, and also lead us to ask two questions. ${ }^{1}$ The first finding is that irregular ordinals, such as derde 'third', seem to take more time to be fully acquired than regular ordinals, such as vierde 'fourth'. Second, regular ordinals all seem to be acquired at (roughly) the same time, which is

\footnotetext{
${ }^{1}$ These two studies differ from the present study in that it includes only Dutch data, and only looks at synthetic ordinals (e.g., vierde 'fourth') and not analytic ones (auto vier 'car four'). The study in Meyer et al. (2018) focusses more on the comparison of cardinal, synthetic ordinal and superlative comprehension and is more exploratory in nature. Meyer et al. (under review) focusses on the differences between comprehension and production. Because of that focus, the children are also about 6 months older on average and the participant pool consists of 4-knowers and CP-knowers only. The comprehension data in those studies are thus more limited than the present study.
} 
usually after children have become fully competent counters (cardinal principle knowers, or CP-knowers). It therefore stands to reason that children acquire these ordinals via a rule, deriving the meaning of the complex whole from its parts: the cardinal root and the ordinal suffix. One question that arises is whether this pattern can be attested for other languages. Another is what a rule-based acquisition pattern means for the relationship between ordinal forms and ordinality: do children grasp (exact, numerical) ordinality along with a given ordinal form, or does perhaps a more transparent but less frequent form such as car (number) three also suffice?

This study therefore investigates the idea of rule-based learning by comparing synthetic (e.g., vierde 'fourth') and analytic (e.g., auto vier 'car four') ordinal acquisition in two languages: Dutch and English. Whereas evidence for the ordinal formation rule in Dutch (informally: cardinal plus -de on low ordinals or -ste on twintig 'twenty' and higher) is quite robust, the evidence for the English rule (cardinal plus -th) may be harder to grasp. Dutch has only one or two irregular ordinals (in Meyer et al. under review and the present paper: derde 'third' and achtste 'eighth'; in Meyer et al. 2018: only derde 'third'); English, by contrast, has three (second, third and fifth). Regardless of how one defines ordinality, the first five and also most frequent ordinals in English do not even hint at a rule or underlying structure. ${ }^{2}$ Thus, in order to accumulate enough positive evidence to formulate a rule, the English learner must be more patient than a Dutch child, whose rule has fewer exceptions to overcome (cf. Yang 2016). This raises the question whether English-speaking children resort to lexical learning, i.e., storing the ordinals one by one as wholes (rather than productively deriving them as complex forms), and whether they would do so for all ordinals. Would they first acquire the lower ordinals lexically and acquire higher ordinals (lexically or via a rule) later on? Or would they 'wait' and acquire the regular forms first, and the irregular forms lexically afterwards?

We find evidence supporting the rule-based account in Meyer et al. (2018, under review), but argue that this is nonetheless remarkable: not only is such a pattern atypical of acquisition patterns found for derivational morphology (which generally follows a lexical pattern initially, and is acquired relatively late, cf. Clark 2014), and inflectional morphology (which typically exhibits a u-shaped or "change for the worse" pattern, e.g., Marcus, Pinker, Ullman, Hollander, Rosen \& Xu 1992; Pinker 1999 and cf. discussion in Meyer 2019), but it also deviates from the slow and stepwise pattern found for cardinal acquisition (e.g., Condry \& Spelke 2008; Le Corre and Carey 2007; Negen \& Sarnecka 2012; Wynn 1992 among many others). Analytic ordinals show a pattern indistinguishable from the regular synthetic one.

This paper first briefly summarizes work on the development of cardinal and ordinal numerals, building up to two questions pertaining to the acquisition of ordinals: (i) to what extent does the acquisition of ordinality rely on a particular form, and (ii) to what extent is the ordinal acquisition pattern language-specific? This leads us to compare different ordinal types in Dutch and English in section 3, highlighting their similarities and differences. We then discuss our hypotheses and predictions (section 4), which we test for both languages in sections 5 and 6 . The results of both tests lead us to conclude that while English and Dutch have considerably different ordinal systems, children acquiring these systems use the same strategy: they use language (i.e., a morphological or syntactic rule) to apply abstract numerical knowledge they developed in cardinal acquisition to the ordinal domain.

\footnotetext{
${ }^{2}$ Obviously, not all of these forms are irregular in the same way, with second being a clear case of suppletion, for example, while in fifth the ordinal affix is still accessible and the irregularity is restricted to (phonologically conditioned) root allomorphy. Here we take irregular ordinals to be any synthetic ordinal that does not immediately follow from adding - de (for Dutch) or -th (for English) to a cardinal base.
} 


\section{Numerals in acquisition}

If the claim is that children use knowledge from the cardinal domain in the ordinal domain, then we need to understand how that cardinal knowledge develops before we can compare these processes. Three decades of experimental work on cardinal acquisition provide robust evidence for a tiered pathway in acquisition: all studies show that children, irrespective of their cultural and linguistic background, follow the same slow and sequential pattern, though there is considerable variation with respect to the start and duration of each stage (e.g., Almoammer, Sullivan, Donlan, Marušič, Žaucer, O’Donnell \& Barner 2013; Barner, Libenson, Cheung \& Takasaki 2009; Condry \& Spelke 2008; Huang et al. 2010; Le Corre \& Carey 2007; Le Corre, Li, Huang, Jia \& Carey 2016; Negen \& Sarnecka 2012; Piantadosi, Jara-Ettinger \& Gibson 2014; Sarnecka 2015; Sarnecka, Kamenskaya, Yamana, Ogura \& Tudovina 2007; Wynn 1992 and Meyer et al. 2018). These studies show children acquire the exact meanings of the first four cardinals one by one, progressing through a series of so-called 'knower-levels'. During these initial stages (as pre-knowers, one-knowers, two-knowers, three-knowers and four-knowers), children only have an exact understanding of cardinals up to and including the highest cardinal in that stage, while all higher numerals denote only 'more' than the highest cardinal they know. Because these children only know a subset of the cardinals they can recite in their count list, they are collectively referred to as 'subset-knowers' (Le Corre et al. 2006).

By contrast, children in the final stage of cardinal acquisition, CP-knowers (or cardinal principle knowers), are fully competent counters who can infer the meanings of all the remaining cardinals in their count list, thereby making the counting routine productive. These children know that answering the question how many means applying at least three counting principles (see also Gelman \& Gallistel 1978): the one-to-one correspondence principle (every cardinal belongs to one counted item), the stable order principle (the count list has a strict order), and the cardinal principle (the numerosity of the set is equal to the last number counted). Children may reach this stage by the age of three, though many children are well into their fours when they make this conceptual leap (e.g., Huang, Spelke \& Snedeker 2010; Le Corre \& Carey 2007).

The step from subset-knower to CP-knower has been linked to two innate, non-linguistic, cognitive systems that can be used to represent numerical concepts: the Object Tracking System (OTS), which allows for precise representations of sets of up to three or four individual items, and the Approximate Number System (ANS), which allows for inexact, ratio-sensitive representations of larger quantities. In order to overcome the limitations of each system and achieve precise representations of quantities over four, these two systems need to be combined (e.g., Le Corre \& Carey 2007). We refer the reader to Sarnecka (2015) for a recent and more detailed overview of children's development of numerical knowledge.

Much less robust evidence is available for ordinal acquisition, but those studies collectively suggest that the procedure there is quite different from the cardinal one, despite the overlap in the required conceptual knowledge. The only difference is that the cardinality principle is exchanged for the ordinality principle, as the counting procedure here answers the question of which one rather than how many. The last count now represents the ordinality of the last item, not the cardinality of all items counted. Given these similarities, one might speculate (as do Meyer et al. 2016) that there is nothing conceptually more complex about picking out an individual from a set (ordinality) than representing the entire set (cardinality); acquiring ordinals should thus be no different, or at least no more difficult, than acquiring cardinals.

However, direct and indirect evidence suggests there is a difference, as children acquire ordinals later and according to a different strategy than cardinals. Pretest data in Matthei 
(1982) and Hamburger \& Crain (1984) show that many children of CP-knower age fail to understand ordinals such as second and third: $15 \%$ of children aged three to six $(M=5 ; 01)$ in the former study, and $24 \%$ of four-year-olds $(4 ; 05-5 ; 09, M=4 ; 11)$ in the latter. Miller, Major, Shu \& Zhang (2000, Mandarin Chinese) show that children can count higher using cardinals than ordinals, while Fischer \& Beckey (1990, English), Colomé \& Noël (2012, French) and the Meyer et al. studies), all saw higher scores on cardinal comprehension conditions than ordinal ones. There is also evidence to suggest learners acquiring a regular ordinal system such as Chinese do so at an earlier age than learners of English, which has a highly irregular count list (Miller et al. 2000). They report that American six-year-olds still struggle with ordinals $34 \%$ of the time, but note that this is a mean score: 17 out 31 children obtained a perfect score, meaning that a little less than half must have performed well below chance. Though regularity effects within languages are less clear (cf. Meyer et al. 2018 for Dutch, Trabandt, Thiel, Sanfelici \& Schulz 2015 for German), and Miller et al. cannot offer any detailed pattern for ordinal acquisition in English, this finding alone suggests that ordinals (at least in English) are acquired quite abruptly, rather than incrementally.

This idea is supported by the studies in Meyer et al. (2018, under review), which provide cleaner and more robust evidence that (ir)regularity affects both the timing and pattern of ordinal acquisition in Dutch. Their data, from two 'Give Me' type comprehension tasks (Wynn 1992, Colomé \& Noël 2012) and a 'Tell Me' production task (Colomé \& Noël 2012), show that exceptions to the ordinal formation rule are acquired after forms that do follow the rule. In production, children make fewer errors on regular forms such as vier-de 'fourth' than on irregular der-de 'third' and acht-ste 'eighth' (which takes the suffix typically found on higher ordinals in Dutch). In comprehension, the difficulty with achtste 'eighth' is less clear, but derde 'third' is clearly problematic. Moreover, children are much better at comprehending the ungrammatical but regularized counterpart of derde, namely *driede 'threeth', which is also found in children's (elicited and spontaneous) production. Children also make overgeneralization errors on achtste, producing *achtde instead. ${ }^{3}$ They therefore argue that the stepwise pattern found for cardinals (in which knowing a given numeral entails knowing all preceding numerals) does not hold for ordinals, and that children use ordinal morphosyntax to acquire ordinal meaning, i.e., ordinals are acquired in a rule-based fashion, at least in Dutch. They describe the developmental pathway given in (1).

Stages in ordinal acquisition (adapted from Meyer et al. under review, page 4):

(i) Children use morphosyntactic cues (such as the fact that ordinals combine with singular nouns whereas most cardinals combine with plurals) to discover that ordinals refer to individuals, not sets.

(ii) Children, when they are at least four-knowers, acquire eerste 'first' first. This form is acquired relatively early for three reasons. It does not require true counting competence, it is roughly $45 \%$ more frequent in spoken Dutch than tweede 'second' through twintigste 'twentieth' combined (see Table 1, this paper), and it has been shown to be a regular superlative (rather than an ordinal) in Dutch (Barbiers 2007).

\footnotetext{
${ }^{3}$ They also found some instances of -ste overgeneration, namely negen-de 'ninth' produced as negen-ste, but they consider this to be an effect of the numeral's proximity to achtste 'eighth'. A reviewer of the present paper wondered whether the difficulty in comprehension or production is due to achtste containing an unusual consonant cluster, but note that the pronunciation of this ordinal in Standard Dutch is [axtstə], which is simpler than orthography suggests. This combination of consonants is also found elsewhere, such as in zachtste 'softest' [zaxtstə]. The [t] in the root is often elided in these cases, which may affect transparency, but the phonological complexity is comparable to ordinals formed with -tig [tix] (e.g., twintigste 'twentieth').
} 
(iii) Shortly thereafter, children acquire the ordinal formation rule (informally: cardinal + suffix $=$ ordinal). Children in this stage comprehend at least low, regular ordinals such as tweede 'second, lit: two-th' and vierde 'fourth'.

(iv) Extra-linguistic factors influence performance on higher, regular ordinals: the further one has to count and maintain one-to-one correspondence, the more demanding the task becomes. Knowledge of higher ordinals is by definition limited to CP-knowers only, since children who cannot count beyond four cannot be expected to count to higher ordinals either.

(v) Performance on irregular forms (derde 'third' in comprehension and production, and achtste 'eighth' in production) improves after acquisition of the rule. Note that this might be before or after performance on higher ordinals improves.

The stages show that while cardinal knowledge and age play a role, as does the place in the ordinal count list, the most influential factor in this process is the ordinal form itself. To explain the developmental pattern in (1), the claim is that ordinals are acquired "from the inside out" rather than "from the outside in": children arrive at a correct interpretation of an ordinal by actively treating it as a complex form, i.e., deriving the meaning of the whole from its parts, rather than lexically acquiring a number of ordinals as simplex forms that are then later seen as complex, i.e., the product of a productive rule. In other words, the claim is that children recognize that the ordinal vierde 'fourth' consists of a cardinal root four and a suffix -th, and hence must differ in meaning from the cardinal alone. After applying the relevant counting principles to the cardinal root, they can then add on the semantic contribution of the ordinal suffix (which is to denote an individual rather than the cardinality of a set) and arrive at the appropriate interpretation of the whole. This approach works for both comprehension and production, but only for regular ordinals. Root allomorphy can be confusing: some children, when asked to find de derde 'the third', claim er is geen der 'there is no der', or produce *driede 'threeth' when asked to name the third place in line. This suggests they recognize the ordinal structure, consisting of an ordinal suffix and a cardinal root, and attempt to apply the rule, but fail in identifying the allomorph as such. The rule comes first, and exceptions are acquired lexically later on. The claim here is that ordinals are productive in adults and children; how they are ultimately processed or represented is a topic for future study. While each simplex cardinal possesses its own lexical entry in the Mental Lexicon, complex cardinals and ordinals (both regular and irregular) could be processed via morphological decomposition in addition to being stored.

A rule-based approach to acquisition explains why the children in Meyer et al. (2018, under review) have difficulty with irregular forms while mastering regular ones, even regular ordinals that are much less frequent and further down the count list. However, this approach is surprising given what is known about the acquisition of derivational morphology: while derived forms may appear quite early in children's speech, it takes time for them to use most affixes productively (Clark 2014). Indeed, Clark (2014) notes that children learn individual (complex) forms lexically at first, and need to collect sufficient evidence for their morphological complexity in order to generalize over these examples and form a productive rule. She points out that this process is affected by the productivity of the rule, as well as by the identifiability and transparency of both the root and the affix. This would lead us to expect ordinal numerals to be a product of storage (lexical learning), rather than computation (rule-based learning), though two questions now arise.

The first is whether the specific ordinal form is critical in grasping ordinal meaning or whether difficulties in comprehension can be avoided by using a different structure altogether: Meyer et al. (2018) only look at synthetic ordinals. While they do show the 
opacity in derde 'third' is resolvable via overgeneralization (i.e., *driede 'threeth'), perhaps a syntactically derived (analytic) ordinal such as hoofdstuk (nummer) drie 'chapter (number) three' also suffices (cf. discussion in Meyer et al. under review). While such forms are intuitively much less frequent, and have a different semantic flavor, the underlying cardinal base is completely transparent. Comparing such forms to (ir)regular synthetic ordinals such as derde 'third' and vierde 'fourth' may be a way to approach the relationship between the transparency, form, and frequency of ordinals in acquisition. We return to this in section 3 .

The second question is how language-specific the pattern is. Most ordinal acquisition studies to date focus on languages with an ordinal system more regular than the Dutch one (i.e., Chinese, French, and German, cf. Miller et al. 2000, Colomé \& Noël 2012, Trabandt et al. 2015), but the appeal of the rule might decrease in less transparent systems. The existing literature provides us with no means to tell: there is no study (to our knowledge) that directly and precisely investigates the age and order of acquisition of ordinals within a more irregular ordinal system (such as the English one) and/or compares the acquisition of ordinals between a (relatively) regular ordinal system (such as Dutch) and an irregular one (such as English). The goal of this study is to do just this: we extend the work carried out for Dutch (by replicating the cardinal and synthetic ordinal patterns, and adding on analytic ordinals and overgeneralized forms) and compare these results to a similar task set up for English.

\section{Ordinals in Dutch and English}

Dutch and English have considerably different ordinal count lists. Putting aside eerste 'first' (a superlative, cf. Barbiers 2007), Dutch has one irregular ordinal, morphophonologically irregular derde 'third', and two ordinal suffixes: -de (used for nearly all of the first nineteen ordinals) and -ste (for higher ordinals and achtste 'eighth'). Two forms thus provide evidence for the ordinal formation rule early on in the count list, within the boundary of the Object Tracking System (OTS). English only has one ordinal suffix, namely -th, but English learners are confronted with a different challenge: reliable evidence for the English ordinal rule only appears from sixth on, past the OTS boundary, and the irregularities are all of a different nature (e.g., suppletion, vowel reduction, metathesis). The actual mechanism of the rule is otherwise the same, as the suffix attaches to the rightmost part of the cardinal base, and the ordinal meaning takes scope over the entire numeral.

Table 1 provides an overview of the first twenty cardinals and ordinals in Dutch, including their frequencies in the Corpus Gesproken Nederlands 'Spoken Dutch Corpus' (Oostdijk 2000), and the frequency data for the first twenty ordinals in English, taken from the spoken section of COCA (Corpus of Contemporary American English (Davies 2008). ${ }^{4}$ The CGN data were taken from Meyer et al. (2018). The COCA data were found by searching for each of the individual ordinals tagged as such. The CGN contains approximately 9 million words in 1000 hours of speech files from the Netherlands and Flanders; COCA has nearly 110 million words taken from transcripts of over 150 television and radio programs. The absolute frequencies for both languages represent the frequency per million words and the relative frequencies represent the proportion of occurrences of each ordinal relative to all ordinals tallied in the table for that language. Put differently, out of every million words in Dutch as tallied in the CGN, roughly 2061 are ordinals between eerste 'first' and twintigste 'twentieth', and of these ordinals, some 387 of them (18.79\%) are tweede 'second'.

\footnotetext{
${ }^{4}$ Frequencies in child-directed speech in CHILDES are too low to provide meaningful insight in ordinal use, other than that the evidence for them as a group is scarce.
} 
Table 1: Absolute (per million words) and relative frequencies of the first twenty ordinals in Dutch and English. Data taken from the CGN (Oostdijk 2000) and COCA (Davies 2008). Exceptions to the ordinal rule are printed in bold.

\begin{tabular}{|c|c|c|c|c|c|c|c|c|}
\hline & \multirow[b]{2}{*}{$\#$} & \multicolumn{4}{|c|}{ Dutch } & \multicolumn{3}{|c|}{ English } \\
\hline & & Cardinal & Ordinal & Abs. Freq. & Rel. Freq. & Ordinal & Abs. Freq. & Rel. Freq. \\
\hline \multirow{4}{*}{$\begin{array}{l}\text { Within } \\
\text { OTS }\end{array}$} & 1 & één & eer-ste & 1214.11 & $58.90 \%$ & first & 1260.40 & $71.45 \%$ \\
\hline & 2 & twee & twee-de & 387.33 & $18.79 \%$ & second & 287.89 & $16.32 \%$ \\
\hline & 3 & drie & der-de & 151.44 & $7.35 \%$ & third & 111.82 & $6.34 \%$ \\
\hline & 4 & vier & vier-de & 69.89 & $3.39 \%$ & four-th & 36.55 & $2.07 \%$ \\
\hline \multirow{12}{*}{$\begin{array}{l}\text { Beyond } \\
\text { OTS }\end{array}$} & 5 & vijf & vijf-de & 40.22 & $1.95 \%$ & fif-th & 23.27 & $1.32 \%$ \\
\hline & 6 & zes & zes-de & 37 & $1.79 \%$ & six-th & 12.22 & $0.69 \%$ \\
\hline & 7 & zeven & zeven-de & 17 & $0.82 \%$ & seven-th & 8.71 & $0.49 \%$ \\
\hline & 8 & acht & acht-ste & 10.78 & $0.52 \%$ & eight-th & 7.83 & $0.44 \%$ \\
\hline & 9 & negen & negen-de & 9.67 & $0.47 \%$ & nin-th & 7.96 & $0.45 \%$ \\
\hline & 10 & tien & tien-de & 17.89 & $0.87 \%$ & ten-th & 3.23 & $0.18 \%$ \\
\hline & 11 & elf & elf-de & 7.78 & $0.38 \%$ & eleven-th & 0.68 & $0.04 \%$ \\
\hline & 12 & twaalf & twaalf-de & 9.67 & $0.47 \%$ & twelf-th & 0.57 & $0.03 \%$ \\
\hline & 13 & der-tien & der-tien-de & 8.22 & $0.40 \%$ & thirteen-th & 0.35 & $0.02 \%$ \\
\hline & 14-19 & cardinal & cardinal-de & 65.78 & $3.19 \%$ & cardinal-th & 1.75 & $0.10 \%$ \\
\hline & 20 & twin-tig & twin-tig-ste & 14.67 & $0.71 \%$ & twentie-th & 0.85 & $0.05 \%$ \\
\hline & \multicolumn{3}{|l|}{ Total } & 2061.44 & $100 \%$ & Total & 1764.08 & $100 \%$ \\
\hline
\end{tabular}

Table 1 shows that both Dutch and English exhibit a similar frequency pattern, in which eerste and first are by far the most frequent, with tweede and second trailing behind and all other frequencies quickly dropping to extremely marginal levels. ${ }^{5}$ Note that we follow Barbiers (2007) and consider eerste 'first' to be a superlative adjective, rather than an irregular ordinal; eerste shares a number of syntactic properties with superlatives that ordinals do not. ${ }^{6}$ This means that Dutch has just one true exception to the rule (derde 'third'), whereas English has three (second, third within the OTS boundary, and fifth beyond it), since ordinals for 'one' are no longer candidates for the ordinal rule.

Table 1 provides an overview of synthetic (morphological) ordinals, but both languages also have the option of deriving ordinals syntactically to express ordinality, such

\footnotetext{
${ }^{5}$ The patterns in Dutch and English are similar, but not the same: there is somewhat more variation in Dutch and the higher ordinals are less infrequent than in English (though cf. Dehaene \& Mehler 1992). In fact, ordinals sixth through twentieth together only count for $2.49 \%$ of the attested ordinals, whereas Dutch zesde through twintigste count for $11.57 \%$. Possible reasons for such differences may include war references for eerste and tweede (de tweede wereldoorlog 'the second world war' is fine, but *Wereldoorlog 2, a direct translation of English World War 2, is not) or how speakers talk about past centuries (one would say de achttiende eeuw 'the eighteenth century' in Dutch, whereas the 1700s is also possible in English). We did not investigate the differences in detail, but expect the occurrence of such forms in child-directed speech to be minimal. Another difference is the relatively high frequency of tiende compared to tenth in English and the immediately preceding ordinals in Dutch. We can only guess: fractions (drie tiende would result in a hit for Dutch, but three tenths would not in English), spelling/parsing errors (e.g., vijftiende misspelled as vijf tiende, whereas teenth is unlikely to appear on its own), or the inclusion of sports commentaries in the Dutch corpus (where top ten lists are intuitively likely to occur) might account for some of these differences.

${ }^{6}$ Whereas eerste can modify plural nouns, lose its final schwa (eerst 'first', but *achtst 'eighth'), and be intensified by aller- 'very' (allereerste 'very first', but *allerachtste 'very eighth'), ordinals cannot. Diachronically, eerste also had (and to some extent still has) recognizable, regular degrees of comparison: positive eer 'fore' and comparative eerder 'former'.
} 
as hoofdstuk drie 'chapter three' (cf. Hurford 1987; Barbiers 2007).7 As Barbiers (2007) points out for Dutch, analytic ordinals differ from synthetic ordinals in both form and meaning: synthetic ordinals have a context-dependent reference (like definite descriptions do) whereas analytic ordinals have a constant reference like proper names do. For example, door (number) three might be the second door that is opened in the classic Monty Hall problem, or participant vier 'participant four' might actually be the tenth participant you ran for your language acquisition experiment. The sentences in (2) through (5) compare analytic ordinals to synthetic ordinals and proper names in both Dutch and English.
a. *(Het) vijfde boek verscheen in 2000 .
b. *(The) fifth book appeared in 2000 .
a. *(Het) boek vijf verscheen in 2000 .
b. *(The) book five appeared in 2000 .
a. *(De) Violet is slimmer dan de graaf.
b. *(The) Violet is smarter than the count.

\section{a. *(De) Graaf Tel is grappig maar Graaf Olaf is een engerd. \\ b. *(The) Count Count is funny but Count Olaf is a creep.}

These examples show that while synthetic ordinals precede the noun and require a (definite) determiner, analytic ordinals follow the noun and essentially take the place of the determiner (which is obligatorily absent, as is the ordinal suffix). ${ }^{8}$ Barbiers (2007), citing Siloni (1994) and Longobardi (1994), therefore tentatively suggests that in analytic ordinals, the head noun raises to D, similar to the N-to-D movement in construct states. Though Barbiers (2007) does not provide a full analysis (and neither will we), this type of analysis has also been proposed for related constructions in Dutch, namely title constructions, such as those provided in (5) for comparative purposes, and date constructions, such as drie februari 'three February' versus de derde februari 'February third, lit: the third February', which both mean February third (De Belder 2007, 2009). We leave the (analysis of) similarities and differences for future research to explore, but introduce the analytic forms here because they seem to behave similarly in Dutch and English, and address an important issue we briefly mentioned above: they help to disentangle effects of form (transparency, and morphology versus syntax) and frequency.

One final note on form: we take irregular ordinals in acquisition to be any ordinal that is not analytic and does not immediately and straightforwardly follow from adding a suffix -de (for Dutch) or -th (for English) to a transparent cardinal base. Though theoretically not all irregular ordinals are equal (irregularity could be phonologically driven, a case of root allomorphy, or a case of suppletion), second, third, fifth and derde 'third' are all considered (equally) irregular in our analysis. There are two reasons for this, one practical one and one that is more hypothesis-driven. For one, each type of irregularity occurs only once, immediately confounding the type of irregularity with at least the place of the numeral in the count list and the frequency of that numeral. This makes it practically impossible to

\footnotetext{
${ }^{7}$ We are aware that some adult speakers of both Dutch and English might require a certain context or situation to use analytic forms, and/or the use of the noun nummer/number to make the utterances more natural. However, as the results will show, these forms were unproblematic for the children we tested. We therefore put concerns regarding unnaturalness in our test design or outcome aside for now.

8 A full comparative analysis of synthetic and analytic ordinals might also address archaic or literary forms of the type book the third, as found for example in Lemony Snicket's A Series of Unfortunate Events or Charles Dickens' A Tale of Two Cities.
} 
relate potential differences (or similarities!) in comprehension between second, third and fifth to the type of irregularity. Though it might be tempting to expect fifth to be easier to recognize, it is also further down the list and much less frequent than second or third and we have no a priori way to determine how these factors interact with each other. Second, if the working hypothesis described above is that ordinal acquisition is rule-driven and ordinals are acquired 'from the inside out' (the meaning of the whole is acquired by acquiring the meaning of its parts), then any deviation from the rule is essentially problematic because it requires more than adding or subtracting an ordinal suffix. For Dutch, there is also the question of which of the two ordinal suffixes is the default option. There could be a case for arguing that achtste 'eighth' is the only regular ordinal under 20 (as -ste attaches to more stems than -de), but given that learners form rules on the basis of the input (and not all possible input), and the frequency data (Table 1) suggest that ordinals ending in -ste are even more scarce than ordinals with -de, we take achtste 'eighth' to be irregular here, despite the fact that it is morphologically decomposable into a transparent stem and an ordinal suffix. To be clear: a different categorization of what is (ir)regular would have to be motivated on theory-internal grounds, could lead to different predictions for acquisition, and could also have consequences for the analysis and interpretation of the experimental data later on. Since the purpose of this paper is not to test all theoretically conceivable rules or categorizations, we leave it to further research to flesh out these differences in child and/or adult language.

\section{Hypotheses and predictions}

The present study investigates the hypothesis that children make use of the ordinal form to acquire ordinal meaning (put forward in Meyer et al. 2018, under review), extends its linguistic domain from Dutch to English, and pits this view against frequency (and, indirectly, type-specific meaning). For both languages, we test cardinal knowledge as a reference point to which we can compare children's ordinal knowledge. We focus on comprehension.

Obviously, we expect no remarkable differences in cardinal knowledge between Dutch and English learners (though English learners are reported to become CP-knowers some months before what was found for Dutch learners, cf. Meyer et al. 2018). We also do not expect differences between the Dutch children in the current study and earlier studies reporting on Dutch children's ordinal performance - at least for the same condition types. Thus, we expect to find an effect of (ir)regularity in synthetic ordinals, as well as an effect of knower-level and/or age. Moreover, regularized *driede 'threeth' should not pose a problem for children who understand other regular ordinals, even if derde 'third' does: though absent from the input, this ungrammatical form does follow the ordinal formation rule the children are hypothesized to have formulated.

If English-speaking children acquire ordinals in the same way Dutch learners do, then we predict a clear effect of (ir)regularity here, too: we expect children to do better on regular ordinals than on irregular ordinals. And here, too, ordinal comprehension should arise around the CP-knower stage of cardinal acquisition, and hence we expect an effect of knower-level and/or age (the two have been shown to be correlated (Meyer et al. 2018, under review). This means that performance on specific ordinals between the languages should differ: because Dutch tweede 'second, lit: two-th' is regular, performance here should be higher than on English irregular second. Overall (on all ordinals combined), this means that English learners should do worse than Dutch children, because they have more irregular forms (exceptions) to acquire, which need to be learned lexically. If the number of exceptions affects the speed of acquisition of the rule, then English learners should not only have lower comprehension scores on irregular forms, but also on regular forms. 
Note, though, that acquisition speed need not be affected; perhaps the English learners receive sufficient input despite these exceptions - more evidence does not necessarily imply quicker or easier acquisition.

However, it may be that the number of exceptions in the English ordinal list discourages a rule-based approach to ordinal acquisition altogether. In this case, English learners could fall back on other properties, such as token frequency. Then we expect (at least the first five) ordinals to be acquired lexically. Differences in scores on individual ordinals would then not be the result of their irregularity, but of their place in the count list (as lower ordinals are more frequent than higher ordinals). Higher ordinals could then be acquired either via a rule or lexically. Moreover, if Dutch learners are typically helped by the ordinal rule, and English learners cannot benefit from such a rule, then we expect lower scores overall in the English group. Put differently, English learners would be slower than Dutch learners. Adult speakers of English obviously can derive ordinals from any cardinal (and hence have accrued enough evidence to form a rule); the issue is whether children are able to take in or treat sufficient positive evidence from the input to form a rule at all.

We can use the Tolerance Principle and the Sufficiency Principle to determine when children (or adults) will form a rule, given the (counter)evidence the learner has (Yang 2016). ${ }^{9}$ These principles state that a rule can and will generalize if, and only iff, (i) the number of explicitly attested exceptions is lower than the number of items in the category $N$, divided by the natural $\log$ of $N$, and (ii) the number of rule-following attestations subtracted from the total number of items in the category $N$ is lower than the number of items in the category $N$, divided by the natural $\log$ of $N$. This is formalized as in (6) and (7).

The Tolerance Principle (Yang 2016: 8)

"If $R$ is a productive rule applicable to $N$ candidates, then the following relation holds between $N$ and $e$, the number of exceptions that could but do not follow $R$ : $e \leq \theta_{N}$ where $\theta_{N}=\frac{N}{\ln N}$."

(7) The Sufficiency Principle (Yang 2016: 177)

"Let $R$ be a generalization over $N$ items, of which $M$ items are attested to follow $R$. $R$ can be extended to all $N$ items if and only iff: $N-M<\theta_{N}$ where $\theta_{N}=\frac{N}{\ln N}$."

Although at first glance the two principles might seem identical, the formalisms are different for a reason: whereas the Tolerance Principle is an evaluation measure focused on explicit counterevidence for a given rule $R$ (the exceptions), "Sufficiency, by contrast, asserts that unless the Sufficiency threshold has been crossed, learners are in a state of ambivalence regarding the $(N-M)$ items with which they have no direct experience." (Yang 2016: 178) In other words, children do not generalize a rule to unattested forms if the sufficiency threshold is not met. The two principles balance out how much evidence is enough to generalize over unknown forms, and how much counterevidence is tolerable to maintain a given rule. Note that the outcome (rule or no rule) depends on the amount of evidence a learner has at any given time (here: vocabulary size).

\footnotetext{
${ }^{9}$ See Yang (2016) for the full derivation and motivation for these principles and formalisms, as well as morphological, syntactic and prosodic examples that follow these principles. Basically, the focus is on the breakeven point between storage and computation, i.e., the time it takes to store all items lexically versus the time needed to form a productive rule. If a rule is productive, the learner cannot apply it until all exceptions have been considered and rejected. The time it takes to consider each exception depends on its frequency (rank in the list of exceptions, which follows an assumed Zipfian distribution). Hence, $e$ in the formulas in (6) and (7) could be read as a unit of time, and the formalisms as a more mathematical approach to the Elsewhere Condition (Anderson 1969; Kiparsky 1973).
} 
Given these principles, English-speaking children would need to know five ordinals total in order for English ordinal formation to be considered productive in children, despite the exceptions second, third and fifth. (If $N=5$, then $\theta_{5}=3.1$, which is greater than 3.) This means that just two regular ordinals (e.g., fourth and sixth) would then be enough to acquire the ordinal formation rule. If first is considered a candidate for the rule $R$ (bringing the number of exceptions up to four), then the total number of $N$ candidates must be nine, meaning now five rule-abiding forms are necessary. Either case would require the English learner to be in the CP-knower domain to know a sufficient number of cardinal roots to which the rule could apply. This would require the learner to somehow store evidence for the rule before actually being able to use the ordinal forms it has stored (as previous work provided no evidence for an initial stage of lexical acquisition of derde 'third' in Dutch). ${ }^{10}$ Note that the Dutch learner almost gets the rule for free, because (as Yang points out) learners with small vocabularies (small $\mathrm{Ns}$ ) have a better chance of formulating a rule (small Ns skew towards rule-formation and tolerate a relatively large amount of exceptions. With an $N$ of 2 (tweede 'second' and derde 'third') we would say it is hard to determine which form is the rule and which the exception, but adding in vierde 'fourth' and bringing $N$ to 3 , would mean $\theta_{3}=2.73$, which is greater than the one exception the rule can tolerate, and would even accommodate eerste 'first' as a potential candidate for that rule. This means that Dutch learners could formulate the rule within the domain of the Object Tracking System, while the conceptual basis for the English rule requires merging both number systems. However, it is an open question whether the Dutch learner has an advantage, given that ordinal acquisition seems to commence after children are CP-knowers.

Another issue we need to address is how to explore the roles of form (transparency, and morphological and syntactic ordinals) and frequency. We use highly regular and transparent analytic ordinals (of the type chapter three) for this purpose. Transparency plays an obvious role in the case of irregular synthetic ordinals: if transparency is key, learners (in both language groups) should find analytic ordinals easier to understand than irregular synthetic ordinals. Regular synthetic ordinals (morphological, vierde auto 'fourth car') and analytic ordinals (syntactic, auto vier 'car four') are expected to be equally transparently related to the cardinal, and we therefore expect no differences in performance on the basis of transparency. However, these ordinal types do differ with respect to their form (synthetic ordinals require the use of the suffix but not movement, whereas analytic ordinals require movement but no suffix), and their prevalence in the input. We are assuming that, for the purpose of this study, the (minor) semantic differences will not play a role (though arguably the semantic differences influence the contexts in which they can be used and thus their frequency). In other words, if frequency is most important, then (regular) synthetic ordinals should be easier for children to comprehend than analytic ordinals.

If the form itself matters (i.e., whether the ordinal is derived syntactically or morphologically), then we might expect one form to be preferred over the other. We have no clear predictions about whether suffixation (synthetic forms) or movement (analytic forms)

\footnotetext{
${ }^{10}$ The absence of this initial stage is motivated by the comprehension difficulties that go hand in hand with derde 'third'. Typically, when rules are involved in the acquisition of morphemes, we are looking at a u-shaped or 'change for the worse' pattern in development, with the prototypical example being overgeneralizations in irregular past tense forms: the child initially says went and ate, then temporarily also starts producing *goed and *eated, before the evidence steers him back towards targetlike production (e.g., Marcus, Pinker, Ullman, Hollander, Rosen \& Xu 1992; Pinker 1999). However, it seems unlikely these children would have difficulty comprehending went in the "goed stage, especially since the irregular forms never disappear entirely from the output. Consequently, ordinal acquisition is also unlike acquiring inflectional morphology (cf. Meyer 2019). Discussion of how inflectional morphology is represented, processed and acquired, and how this compares to the ordinals at hand, goes beyond the scope of the present paper.
} 
would be easier, however. On the one hand, zero-derivation may be easier for children than affixation, which suggests the suffix in synthetic forms is a hurdle children need to overcome (see section 2 and Clark 2014). On the other hand, the head movement needed for analytic forms might also be problematic, as movement has been considered a costly operation in child language (cf. Blom \& De Korte 2008; Zuckerman 2001 on verb movement and Dutch L1), and examples of such ordinal or similar constructions are scarce: they are likely limited to constructed names such as kabouter Spillebeen (Spillebeen the Gnome, lit: 'gnome spindlelegs', who features in a Dutch nursery rhyme) and titles (Willem II, 'William the second, lit: William two'). No type of storage helps here: analytic ordinals must be derived and interpreted on the spot.

Including analytic ordinals also provides insight into the difference between grasping ordinals and grasping the ordinality principle. The reasoning in Meyer et al. (2018) is that children use and need linguistic form to grasp ordinal meaning, but they do not show whether this knowledge is tied to specific ordinal forms or ordinality in general. If acquiring ordinality depends on a specific ordinal form, we expect differences in comprehension between synthetic and analytic ordinals. If ordinality does not hinge on any specific form (but on no form or simply having any cues), the precise labels (syntactic or morphological) should be of negligible importance as long as the relationship with the cardinal base is transparent. In short, we are pitting transparency and rules against frequency, expecting children to prefer a 'mechanical' relationship between the ordinal and the cardinal from which it is derived, acquiring regular forms first, and irregular forms lexically later on.

\section{Study 1: Dutch comprehension}

\subsection{Method}

We closely followed previous work on numerical development and adapted the 'Give X' comprehension task described in Meyer et al. (2018) to fit the research questions at hand. As in that previous study, we tested the ordinals eerste 'first' through vierde 'fourth', zesde 'sixth', achtste 'eighth' and negende 'ninth', and their corresponding cardinals (to assess a child's knower-level. We also included middelste 'the middle, lit: middle-est' and laatste 'last', to provide a more equal comparison to superlative eerste 'first', because for all three of these forms, no counting or ordinal morphology is involved, but superlative morphology (which is acquired early, cf., Syrett 2016) is. ${ }^{11}$ In contrast to previous work, we excluded adjectival items, and instead included the analytic ordinal forms for the numerals above, and the analytic counterpart for middelste, namely in het midden 'in the middle', as well as the ungrammatical but regular forms *eende 'oneth', *eenste 'onest', and *driede 'threeth'. Each occurred three times. We also included six items that were introduced with an indefinite determiner een 'a' (e.g., een hobbelpaard mag mee 'a rocking horse gets to come'). ${ }^{12}$ Put differently, of the 87 critical trials in the present study, 48 were reused from Meyer et al. (2018), namely those for cardinals, synthetic ordinals and superlatives. As before, each child was tested at their (pre)school in two twenty-minute sessions, administered within one week of each other.

The experimenter asked the child to help a toy monkey named Jaap pack for a trip. Jaap's things (laminated cards with images of familiar objects and animals on them) were

\footnotetext{
${ }^{11}$ We had no a priori idea about how hard it would be for children to locate the middle, but all children in the studies we modelled the present work on did well on stative locative PP's (e.g., vooraan 'at the front', used as practice items. We therefore expected children to preform quite well on these superlatives.

12 This een-condition was included because of the 'first bias' Meyer et al. (2018) found in children who only understand that ordinals referred to individual items: roughly half of these children always selected the first card, regardless of the ordinal. We consider this een condition neutral, and hence expect a bias to appear only if it is the result of a more general strategy, not if it is driven by something related to the ordinal itself.
} 
all getting in line to jump into the suitcase, and the child was asked to listen to what Jaap wanted and put the appropriate item(s) from the line in the suitcase. Examples (8) through (10) illustrate cardinal, synthetic ordinal and analytic ordinal stimuli, respectively.

Er mogen acht stiften mee. Kun je acht stiften (tellen en) There may.PL eight markers with. Can you eight markers (count and) inpakken voor Jaap?

pack for Jaap?

'Eight markers get to come. Can you (count and) pack eight markers for Jaap?'

(9) Jaap zegt dat de zesde jas mee mag.

Jaap says that the sixth coat with may.SG.

'Jaap says that the sixth coat gets to come.'

Kun je de zesde jas (vinden en) inpakken voor de aap?

Can you the sixth coat (find and) pack for the monkey?

'Jaap says that the sixth coat gets to come. Can you (find and) pack the sixth coat for the monkey?'

(10) Jaap zegt dat slang drie mee mag.

Jaap says that snake three with may.SG.

'Jaap says that snake three gets to come.'

Kun je slang drie (vinden en) inpakken?

Can you snake three (find and) pack

'Jaap says that snake three gets to come. Can you (find and) pack snake three?'

Though the exact formulation varied to keep the game natural, typical stimuli offered children the numeral in a full subject DP. When necessary, the numeral was repeated with either a noun (with cardinals, e.g., negen ballonnen 'nine balloons') and/or a definite article (with ordinals, e.g., de tweede (slee) 'the second sled'). ${ }^{13}$ Children were allowed to count out loud, use their finger to track the objects they counted, and recount ("check and make sure").

The objects for ordinal trials were all identical, depicted from the side and had clear fronts or faces to highlight the direction of the line. The number of objects in line varied per numeral: the lowest numeral trials (one, two, first and second, car one, car two) all occurred with four cards in line; cardinals three, four, and their ordinal counterparts with six cards, and the higher numeral conditions with ten. We presented items in one of eight pseudo-random orders within each session and we counterbalanced which session was administered first between participants. Both sessions started with two stative locative PP's as practice items (in which children had to find the object vooraan 'at the front' and achteraan 'at the back' of the line), and typically ended with a counting session, in which children were asked (to try) to recite the cardinal count list, followed by the ordinal list. They were allowed to use the cards to perform these counting tasks. Children who declined to count were not excluded from analysis as long as they completed the rest of the task.

In addition to following Meyer et al.'s procedure, we also took the same approach in categorizing children's numerical knowledge. We first looked at the responses to the cardinal

\footnotetext{
$\overline{{ }^{13} \mathrm{~N} \text {-ellipsis should }}$ not be an issue because (i) the initial stimulus does contain the full DP and (ii) children as young as 1;8 can use e.g., cardinals, quantifiers, superlatives and/or eerste 'first' to license N-ellipsis in their own speech (Sleeman \& Hulk 2013).
} 
trials to determine each child's cardinal knowledge, by using the knower-level estimation tool provided by Negen, Sarnecka \& Lee (2012, based on Lee \& Sarnecka 2010a; b) and the criteria described in e.g., Le Corre \& Carey (2007). To be considered a 'knower' of a given cardinal under these criteria, a child had to provide the correct number of cards for a given cardinal at least two out of three times when asked for that cardinal, and provide that number of cards no more than once in response to a different cardinal. The tool and the criteria typically led to the same categorization. We gave the child the benefit of the doubt in the few cases where there was a difference and/or where the model was inconclusive (mostly due to minor counting errors on high cardinals.) Three children had to be excluded because their response patterns were so erratic that a knower-level classification was not possible. We determined children's ordinal knowledge in the same way as in Meyer et al. (2018, under review), i.e., by only taking correct responses into account. ${ }^{14}$ We considered a total of 70 typically-developing monolingual Dutch children (38 boys, 32 girls; ages: $32-59$ months, $M=48.7, S D=8.3$ ) for analysis. ${ }^{15}$ We excluded an additional six children for not completing all trials.

\subsection{Results}

The data from the indefinite een ' $a$ ' baseline condition reveal no issues with basic components of the task, and no children were excluded from further analysis on the basis of these trials. When asked to provide, for example, een helicopter 'a helicopter', most children (83\%) always provided a correct response. Only 7 children (10\%) provided more than one card on half (or more) of these trials. Such errors make up $8.3 \%$ of the total number of responses to een 'a' trials. We found no correlations with age or any other factors. We did find that $47 \%$ of children preferred the first card in line, meaning that they selected the first card on more than half of the een-trials. This is in line with what Meyer et al. (2018) describe for responses to ordinals among subset-knowers, where roughly half the children exhibit what they call a "first-bias".

Before turning to ordinals, we need to assess children's cardinal knowledge. Figure 1 is an area plot of the knower-levels by age; Table 2 displays children's ages at each cardinal knower-level.

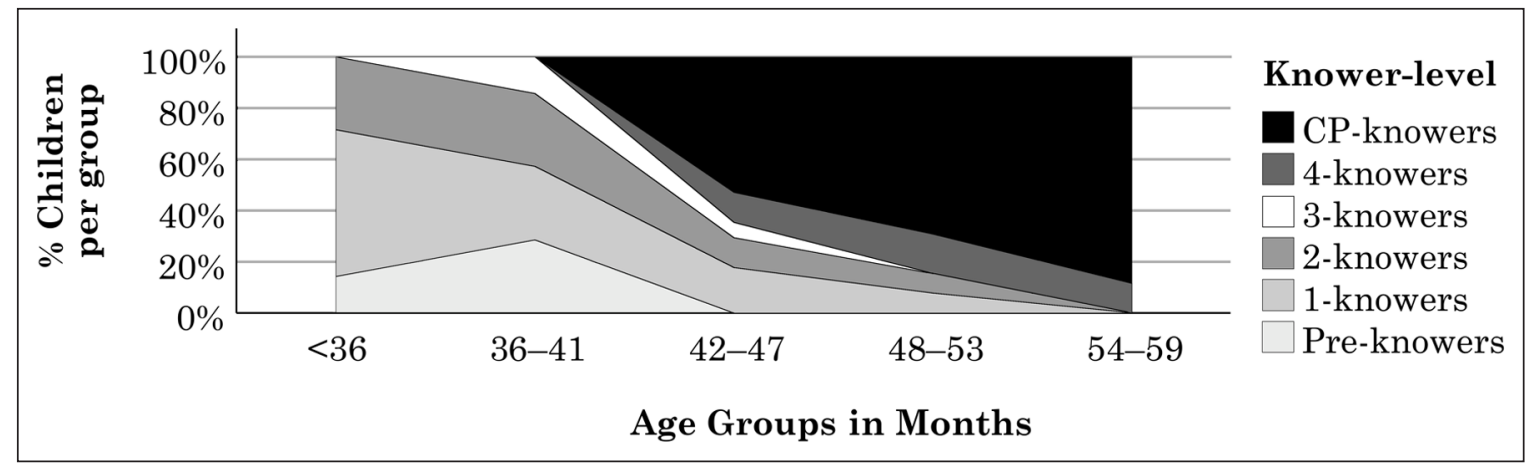

Figure 1: Area plot of knower-level distribution in the Dutch sample per age group in months, i.e. ranging from 3;0 through $4 ; 11$ in in six-month intervals.

\footnotetext{
${ }^{14}$ The reasoning is that ordinal acquisition does not appear to be inherently tiered, and thus we have no way to properly interpret or weight an error. For cardinals, if a child provides e.g., six cards when asked for three, he not only lacks knowledge of three but also of six. For ordinals, by contrast, if the child provides the sixth card when asked for the third, we can only be sure he does not understand third.

${ }^{15}$ Children were not pre-tested for language or developmental disorders within the context of this study. We considered children to be typically developing on the basis of teacher assessments and if they were not enrolled in speech therapy or remedial classes, and were not being screened for language or developmental disorders.
} 
Table 2: Knower-level and age of all participants. Age ranges and means are given in years (year;month) and months, the standard deviations in months only.

\begin{tabular}{|l|r|c|c|c|}
\hline \multirow{2}{*}{ Levels } & \multirow{2}{*}{$\boldsymbol{n}$} & \multicolumn{2}{|c|}{ Age } \\
\cline { 3 - 5 } & & \multicolumn{1}{|c|}{ Range } & Mean & SD \\
\hline Pre-knowers & 3 & $2 ; 11-3 ; 03(35-39)$ & $3 ; 01(36.7)$ & 2.1 \\
\hline 1-knowers & 10 & $2 ; 09-4 ; 01(33-49)$ & $3 ; 03(38.7)$ & 5.7 \\
\hline 2-knowers & 7 & $2 ; 08-4 ; 05(32-53)$ & $3 ; 05(41.3)$ & 7.2 \\
\hline 3-knowers & 2 & $3 ; 01-3 ; 06(37-42)$ & $3 ; 04(39.5)$ & 3.5 \\
\hline 4-knowers & 7 & $3 ; 06-4 ; 10(42-58)$ & $4 ; 04(51.7)$ & 6.0 \\
\hline CP-knowers & 41 & $3 ; 06-4 ; 11(42-59)$ & $4 ; 05(53.2)$ & 5.1 \\
\hline Total & 70 & $2 ; 08-4 ; 11(32-59)$ & $4 ; 01(48.7)$ & 8.3 \\
\hline
\end{tabular}

Both the table and the figure paint a familiar picture: the distribution of children across knower-levels and age groups resembles what was previously described for Dutch in Meyer et al. (2018, under review). As in Meyer et al. (under review), the number of four-knowers is relatively limited and the number of CP-knowers relatively high compared to Meyer et al. (2018), but the overall picture is otherwise comparable and more in line with what was attested for studies focusing on e.g., English. While there is some individual variation with respect to the age at which children are at a certain knower-level, a Spearman's correlation test reveals that children's cardinal knowledge correlates significantly with their age in months $\left(r_{s}=0.692, p<0.001\right)$. Most of the individual variation is found in three-year-olds, as nearly all four-year-olds have reached (or nearly reached) the final stages of cardinal acquisition, while no children younger than 3;06 can be classified as four-knowers or CP-knowers.

Given the similar situation (our dataset only includes ordinal type as an extra factor), we follow a similar statistical procedure to the one in Meyer et al. (2018). We used R (R Core Team 2016) and the lme4 package to fit a generalized linear mixed-effects logistic regression model (Bates, Maechler, Bolker \& Walker 2015) to the data described above. We worked towards a final model in a few steps. We first excluded the synthetic and analytic forms for the first in line (i.e., eerste, *eende, *eenste, and auto één), as well as in het midden 'in the middle', middelste 'middle-est' and laatste 'last'. ${ }^{16}$ All other synthetic and analytic ordinals we tested were included. We then constructed a model with a random effects structure that was as maximal as our data would justify. We included by-subject random intercepts with slopes for ordinal (place in the count list) as a continuous factor and ordinal type (synthetic, e.g., vierde auto 'fourth car', or analytic, e.g., auto vier 'car four'), and by-trial random intercepts with slopes for AgeInMonths*Knower-level. ${ }^{17}$ We included as fixed factors ordinal, ordinal type and regularity (irregular, i.e., derde 'third' and achtste 'eighth', or regular, such as vierde auto and auto vier; all analytic ordinals are inherently regular) and knower-level (continuous) in the initial model. The dependent variable was whether a child's response was correct or incorrect, meaning the formula for this initial model is Correct $\sim$ OrdinalContinuous + Regularity + Type + Knower-

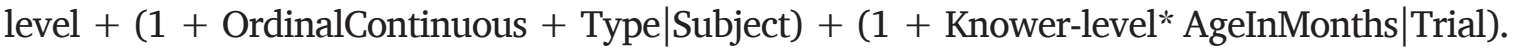

\footnotetext{
${ }^{16}$ Again, we left out eerste 'first' for a priori conceptual reasons: eerste 'first' is a superlative, not a true ordinal (cf. Barbiers 2007).

${ }^{17}$ Including random slopes for regularity led to convergence errors, as did interactions between ordinal and type. The random effects structure here therefore differs from those used in the analysis of the English data and the comparison between the English and (the CP-knower subset of) Dutch data, which do include that interaction. Including ordinal as a categorical factor in the random effects structure led to convergence errors in some steps. We opted to simplify the model rather than eliminate the random slopes completely.
} 
We centered continuous factors and coded categorical factors with explicit contrasts before analysis. No outliers other than those described above were removed.

If we were to follow Meyer et al. (2018), we would go on to investigate whether a child's age was a better predictor for ordinal comprehension than knower-level, comparing a model similar to the one above with one in which knower-level was exchanged for age in months because the two factors are correlated. Following this strategy with our data does show that knower-level is a better predictor than age (model with knower-level: AIC: 1792.8, BIC:1916.9; model with age: AIC: 1809.2, BIC:1933.4). However, here we included both knower-level and age as factors, as well an interaction between these two in the same model. This made the model more complex (Correct $\sim$ OrdinalContinuous + Regularity + Type + Knower-level*AgeInMonths + $(1+$ OrdinalContinuous + Type|Subject $)+(1+$ AgeInMonths*Knower-level|Trial $))$ but led to a significant improvement over the model without age (AIC: 1788.6, BIC: 1924.5; $\chi^{2}=8.2246, d f=2, \mathrm{p}=0.01637$ ), despite the correlation between age and knower-level (correlation of the coefficients for age and knower-level: -0.602).

We then compared this model to one in which ordinal as a continuous factor and regularity are replaced by one in which ordinal is a categorical factor: Correct OrdinalCategorical + Type + Knower-level*AgeInMonths $+(1+$ OrdinalContinuous + Type|Subject $)+(1+$ OrdinalContinuous + Type|Trial). The reasoning, following previous work, is that a simpler model containing ordinal as a continuous variable may not suffice to explain the variance in our data: ordinal is not truly a continuous variable, and it might be that ordinals are acquired at random (and not simultaneously or in order). Moreover, if something about the individual ordinals themselves better explains the data than what we have defined as irregular, then a more complex model with ordinal as a categorical factor should explain more variance. However, the model comparison reveals this is not the case; the more complex model has an AIC of 1801.6 and a BIC of 1955.3, and thus offers no improvement. We therefore retain the model in Table 3, in which ordinal is a continuous factor. ${ }^{18}$

The model reveals significant main effects of ordinal, regularity and knower-level, and a significant interaction between age and knower-level, but no significant main effect of age. Put differently, what matters in ordinal comprehension is the place in the ordinal

Table 3: Result summary for correct responses on tested ordinals in Dutch: $\beta$ coefficient estimates, confidence intervals, standard errors, associated Wald's $z$-score and significance level $(p)$ for all predictors in the analysis. Formula: Correct $\sim$ (OrdinalContinuous + Regularity + Type) + Knowerlevel ${ }^{*}$ AgelnMonths + (1+ OrdinalContinuous + Type|Subject $)+(1+$ Knower-level * AgelnMonths|Trial). Ordinals considered irregular: derde 'third' and achtste 'eighth'.

\begin{tabular}{|l|r|r|r|r|r|}
\hline Predictors & Estimate & \multicolumn{1}{|c|}{ Cl } & SE $\boldsymbol{\beta}$ & $\boldsymbol{Z}$ & $\boldsymbol{p}$ \\
\hline Intercept & -1.331 & $-2.207--0.456$ & 0.447 & -2.981 & 0.0029 \\
\hline Ordinal & -0.271 & $-0.374--0.168$ & 0.053 & -5.145 & $<\mathbf{0 . 0 0 0 1}$ \\
\hline Regularity & 0.950 & $0.397-1.503$ & 0.282 & 3.369 & $\mathbf{0 . 0 0 0 8}$ \\
\hline Type & -0.448 & $-0.896-0.005$ & 0.228 & -1.958 & 0.0502 \\
\hline Knower-level & 1.669 & $1.036-2.303$ & 0.323 & 5.164 & $<\mathbf{0 . 0 0 0 1}$ \\
\hline Age & 0.080 & $-0.026-0.186$ & 0.054 & 1.474 & 0.1406 \\
\hline Knower-level * Age & 0.074 & $0.015-0.133$ & 0.030 & 2.447 & $\mathbf{0 . 0 1 4 4}$ \\
\hline
\end{tabular}

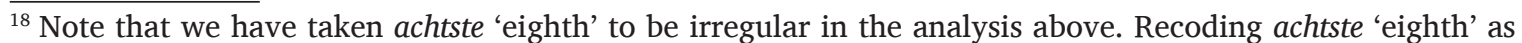
regular did not affect the outcome in the sense that both models show the same effects to be (in)significant, and in the same direction.
} 
count list (higher ordinals are less likely to elicit a correct response) and whether the form follows a regular ordinal formation rule. Whether that is a syntactic rule yielding an analytic ordinal such as auto vier 'car four' or a morphological rule yielding the synthetic ordinal vierde auto 'the four car', does not significantly affect probability of a correct response, though the trend is in favor of synthetic forms (see also Figure 3). It does not generally hold that older children are more likely to provide correct responses. The interaction effect revealed by the model (see Figure 2) clearly shows that age only affects performance in children who have substantial cardinal knowledge in place, and that cardinal knowledge only matters for the two highest knower-levels. This is a meaningful addition to the data in Meyer et al. (2018), who found a main effect of knower-level but did not look at the interaction. Figure 3 shows the percentage of correct responses for

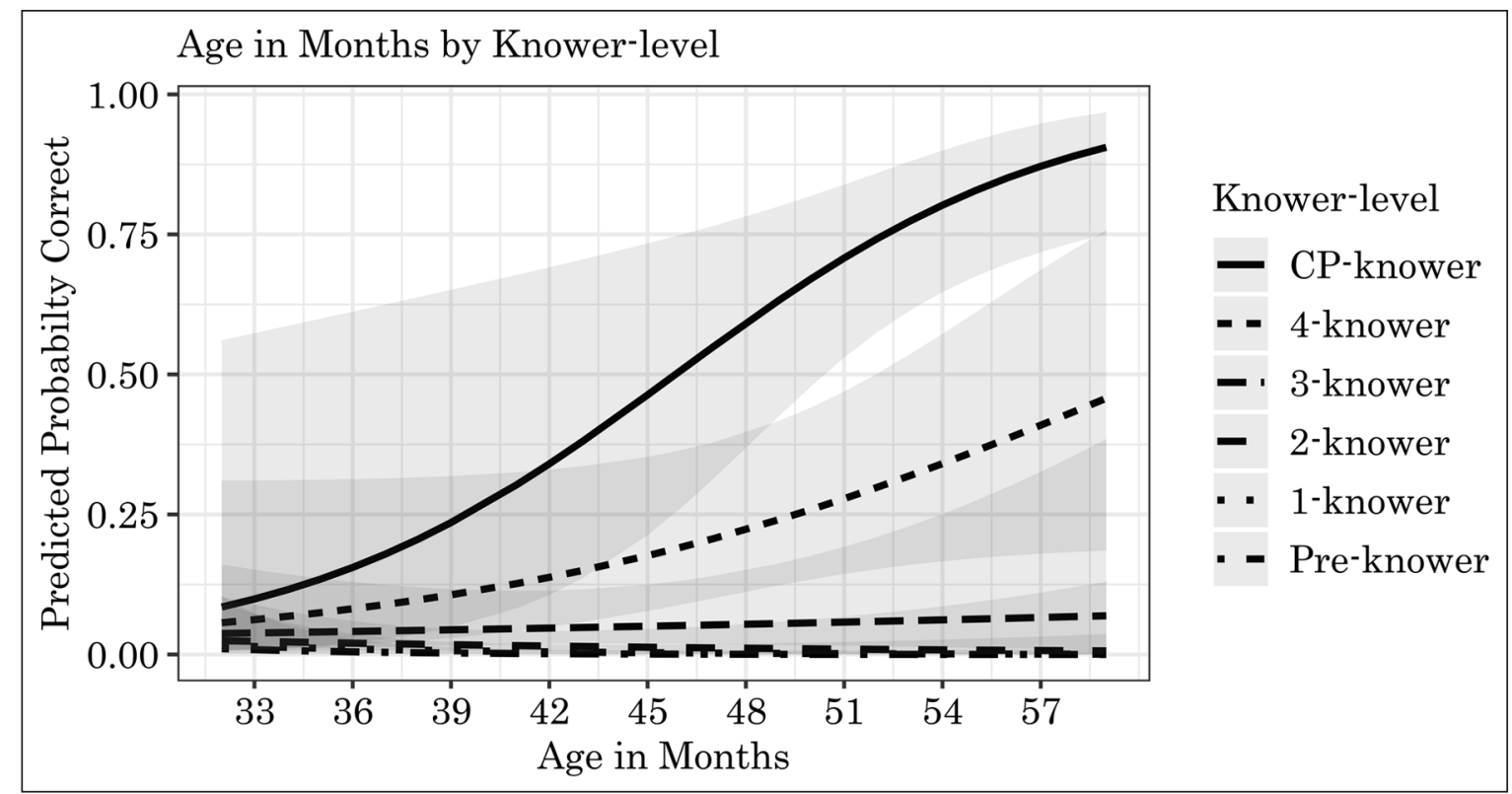

Figure 2: Predicted probabilities of correct responses for the interaction between age and knower-level. The model was run on centered variables; the plot reflects converted scales.

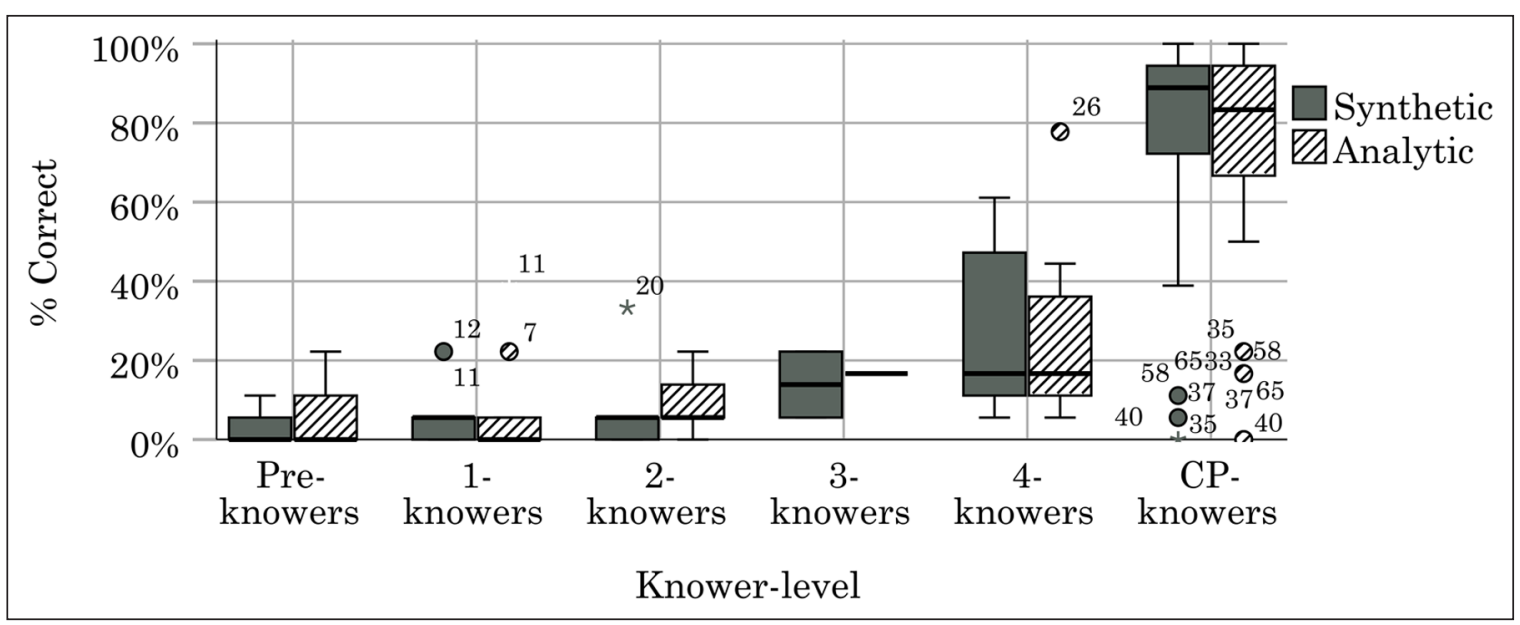

Figure 3: Percentage of correct responses to the synthetic versus the analytic ordinals tested, i.e., tweede, derde, vierde, zesde, achtste, negende ('second', 'third', 'fourth', 'sixth', 'eighth', 'ninth'), and their analytic ordinal counterparts (auto twee 'car two', et cetera), by knower-level. Outliers (circles, $1.5 \times \mathrm{IQR}$ ) and extremes (asterisks, $>3 \times \mathrm{IQR}$ ) are given per participant, represented by their participant number. 
both ordinal types by knower-level in the raw data, underlining that the effect of cardinal knowledge (rather than age) holds for both synthetic and analytic ordinals.

Figures 2 and 3 show that pre-to-three knowers have great difficulty comprehending ordinals in general, regardless of their age or the given ordinal. By contrast, age effects do appear for the highest two knower-levels, where four-knowers perform somewhere in between lower subset-knowers and CP-knowers. The difference is particularly large at the high end of the age range; while younger CP-knowers need not necessarily outperform four-knowers, this does hold for the oldest age groups. CP-knowers score significantly higher than four-knowers (Mann-Whitney $U=101538, Z=-14.157, p<0.0001$, twotailed), and ceiling scores do not appear before the CP-knower stage.

Note that only four of the pre-to-three-knowers provide the correct response to a given ordinal more than once, and only one does so for more than one ordinal. We therefore conclude that children in these lower subset-knower stages lack (systematic) ordinal knowledge. Though not visible in the figures, pre-to-three-knowers do seem to know that an ordinal refers to an individual, since they only select one item from the line.

Figure 4 depicts the percentage of correct scores CP-knowers provided for each cardinal and ordinal included in the model, as well as the superlatives eerste 'first', middelste 'lit: middle-st' and laatste 'last', and in het midden 'in the middle', which here is plotted as the analytic variant to indicate where the middle is. We did not include these latter forms or the raw cardinal scores in the model, but we provide them here for comparative purposes, as they show that performance here was consistently high.

The first observation is that even though CP-knowers are considered to understand all cardinals, performance does decrease for higher cardinals (lightest bars). This pattern is different for ordinals: though performance is better on tweede 'second' and vierde 'fourth' than on the three highest ordinals, performance on these highest ordinals is stable, even for achtste 'eighth'. Second, as the model indicates, we see no difference in correct responses between regular synthetic (medium gray bars) and analytic ordinal forms (darkest bars): both negende auto 'ninth car' and auto negen 'car nine' are equally comprehensible for

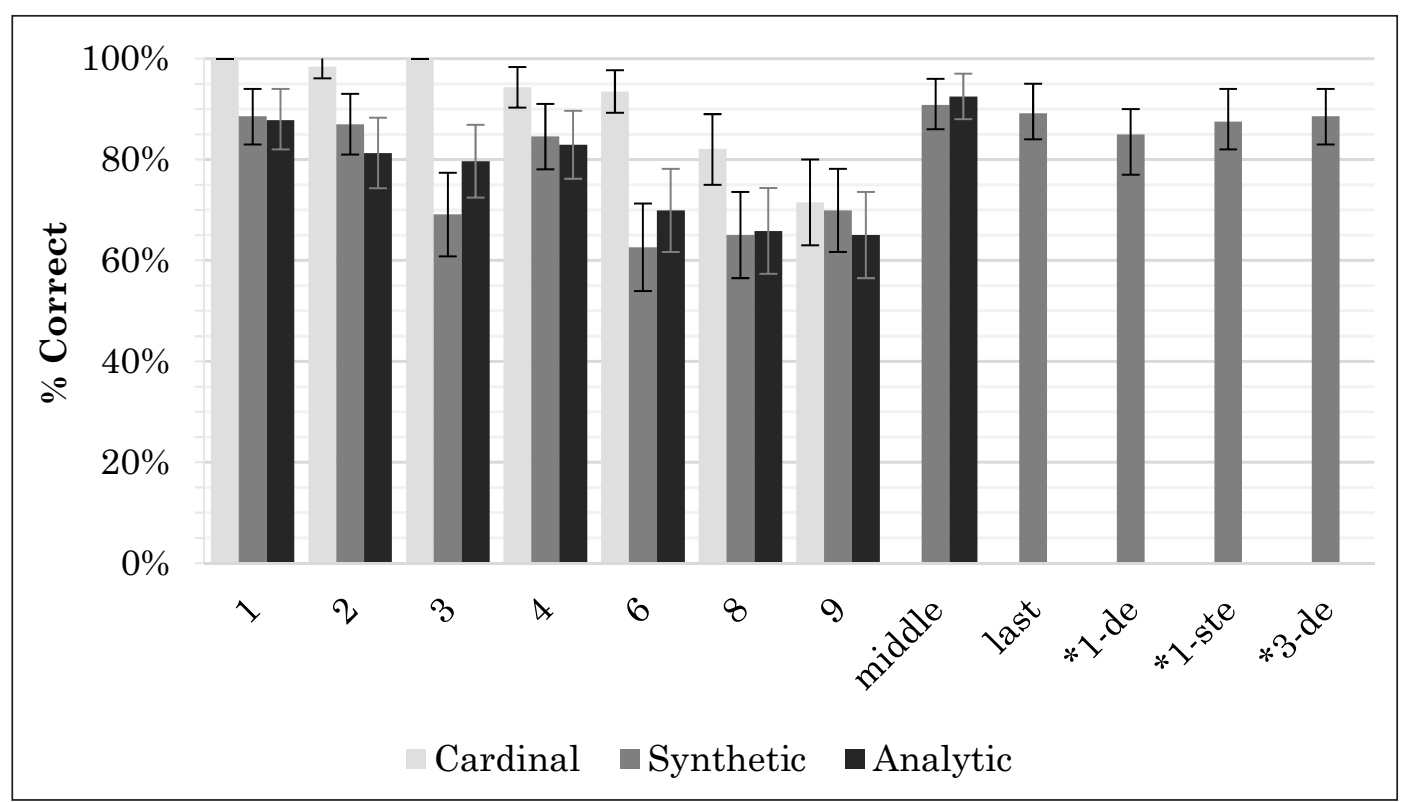

Figure 4: Percentage of CP-knowers' correct responses to all tested numeral conditions (cardinals, synthetic ordinals and analytic ordinals). The last three conditions are regularized yet ungrammatical counterparts for eerste 'first' (*eende 'oneth', *eenste 'one-st') and derde ( ${ }^{*}$ driede 'threeth'). Error bars indicate $95 \% \mathrm{Cl}$. 
example. The most important results, however, pertain to ordinals for three, where the effect of irregularity mentioned above is visible. Children find the derde 'third' less often than "driede 'threeth', and the neighboring ordinals tweede 'second' and vierde 'fourth'. No difference is found between the responses to *driede and auto drie. ${ }^{19}$ In total, 13 CP-knowers were unable to find the derde 'third'. Four of them had difficulty on all ordinals included in the model, but the other nine were able to respond correctly to tweede 'second', *driede 'threeth' and vierde 'fourth' on (at least) two out of three trials, as well as *driede. No children knew only one of the regular low ordinals, and children performed consistently on $98 \%$ of conditions (i.e., responded correctly on all trials in a given condition, or incorrectly on all trials in a given condition). Put differently, the transparent lower ordinals lead to similar performance, whereas irregular derde trails behind. Patterns in the higher ordinal set are less clear, and less consistent overall (with $3 / 3$ or $0 / 3$ correct on a given condition $80 \%$ of the time), but there were no children who exhibited better performance on the three highest ordinals than the lowest ones, and only two children with isolated difficulty with achtste 'eighth'.

As reported in earlier work (see also Section 3), many children would count on these and other ordinal trials, either silently or out loud. For example, when asked for the vierde 'fourth', many children would simply count to four and pack the fourth card, sometimes explicitly adding the ordinal or a concluding remark such as dit is de vierde 'this is the fourth'. They would then also seem to apply this strategy to derde 'third'; some would ask hoeveel is der 'lit: how many is thir' or wat is der 'lit: what is thir', and/or would count (and re-count) the objects in line, sometimes concluding die zit er niet bij 'that one isn't there' or die weet ik niet 'I don't know that one', or openly admitting to guessing or applying some strategy (e.g., it has to be the last card because they know the others are the tweede, *driede, vierde 'second, *threeth, fourth' et cetera). In contrast, mistakes on higher ordinals were never accompanied by such questions or explicit explanations.

\subsection{Discussion}

The data above go against any kind of lexical learning, and instead are in line with a rule-driven pattern in acquisition, though not the most straightforward one. If lexical learning had been at play, we would have expected better performance on derde 'third' than on vierde 'fourth', and not a pattern in which many children cannot find the third item in line but can find its neighbors. The relatively high and consistent performance on analytic ordinals (jas zes 'coat six') is also unexpected under a lexicalist approach: these forms are all but absent from the input, and should at least elicit fewer correct responses than synthetic ordinals (zesde jas 'sixth coat'). Perhaps the most telling evidence, though, comes from children's confused responses to irregular derde 'third': overgeneralization and backformation are unexpected if we assume that the acquisition pathway starts with the storage of whole forms.

Instead, the data align more neatly with previous work that argues in favor of a rulebased pattern. A rule can account for the difference in performance between derde 'third', and regular(ized) forms such as tweede 'second', *driede 'threeth' and vierde 'fourth', and

\footnotetext{
${ }^{19}$ A reviewer requested an additional analysis zooming in on effects of transparency on the ordinals derde, driede and auto drie in CP-knowers. In order to take random effects into account, we ran an additional model on this subset of the data with ordinal form as a categorical factor. We set explicit treatment contrasts with derde as a baseline compared to *driede and auto drie, and otherwise kept the formula close to the original: Correct $\sim$ Form + AgeInMonths $+(1+$ Type|Subject $)+(1+$ AgeInMonths|Trial $)$. The effect of form was significant for derde versus driede $(\beta=7.616, C I=1.899-13.333, S E=2.917, Z=2.611, p=0.0090)$ but not for the difference between derde and auto drie $(p=0.1898)$ or for age $(p=0.3132)$. The difference between performance on derde and auto drie in Figure 4 can therefore be attributed to factors included in the random structure.
} 
the accompanying verbal reactions. Children's questions and comments on these trials suggest that the allomorph obscures the relationship with the cardinal drie 'three', which leads to comprehension difficulties on these trials. (Note that this goes against any kind of 'change for the worse' or U-shaped pattern, as it is unlikely for children to forget a previously stored form.) The analytic and regularized ordinals tested in this study add to previous work by showing that these comprehension difficulties disappear when the opacity is resolved: analytic auto drie 'car three' and the regularized yet ungrammatical synthetic form *driede 'threeth' elicited more correct responses. Moreover, a rule-based account also explains a relatively 'flat' level of performance across all the higher ordinals, as well as the consistent responses on analytic ordinals such as auto drie 'car three': application of a rule should lead to consistent performance. However, such an account does leave us with a question, precisely for this reason: why is performance on higher ordinals lower than performance on tweede 'second' and vierde 'fourth'? Why can children who know a rule not apply this rule across the board?

Note though that the difficulty appears after the same cutoff point in cardinal knowledge, namely the difference between 'low' $(\leq 4)$ and 'high' numerals. (We say appears because we did not test vijfde 'fifth', unfortunately.) There were no CP-knowers who only knew one of the regular low ordinals, so it seems that at least these regular forms are acquired simultaneously. Hence, one way to account for this difference between lower and higher ordinals in the present study, is to say that these children do have a rule, but (can) only apply this rule within the domain of the Object Tracking System (OTS) initially. For vierde 'fourth' only the OTS is needed, whereas both systems are required to reach an exact interpretation for higher ordinals. The learner needs the Approximate Number System (ANS) to represent the larger set and the OTS to represent the individual within that set. As a result, difficulty with higher ordinals arises from having to integrate (co-activate) both core knowledge systems of number in addition to applying the ordinal formation rule. Put differently, some CP-knowers can either apply the rule within the OTS limits (ordinals $\leq 4$ ), or co-activate ANS and OTS (cardinals $\geq 4$ ), but not both. It is worth noting the interaction effect between age and knower-level here: if age only affects performance in children who have substantial cardinal knowledge in place, that means the improvement in ordinal performance follows that conceptual cardinal leap. This is a meaningful addition to the data in Meyer et al. (2018), who found a main effect of knower-level but did not look at the interaction.

This explanation supposes that applying the ordinal rule to higher numerals requires bridging the same critical gap subset-knowers have to bridge to become CP-knowers in cardinal acquisition, which in turn means that combining ANS and OTS is not something the learner does just once, but has to do iteratively. The added difficulty of integrating both systems is equal for all ordinals, which explains why performance across higher ordinals is equal, and would explain why this effect was not found in Meyer et al. (under review): those children were six months older on average, and the only ordinal those children had difficulty comprehending was derde 'third'. Future research would be needed to determine how robust this effect is and whether it is, for example, a relatively short stage limited to children who have just become CP-knowers or whether it is found over prolonged periods of time in all types of CP-knowers. Moreover, though there is a large body of (both behavioral and neural) work that shows ANS functions independently from OTS (in line with the idea that ANS and OTS are not truly 'integrated'), the details of numerical ordinal processing and development have received far less attention (Geary \& Moore 2016, Lyons, Vogel \& Ansari 2016).

We can now maintain that children first recognize that the ordinal vierde 'fourth' consists of a cardinal root four and a suffix -th. They also need to learn (to apply) the relevant 
counting principles to the root, before they can add on the semantic contribution of the ordinal suffix (or, in the analytic case, of the effect of raising the noun past the numeral) and arrive at the interpretation of the whole. If they did not need such principles, more subset-knowers would be able to comprehend at least some ordinals, not just older fourknowers (who are perhaps on the cusp of acquiring the cardinal principle anyway). An open question is whether the OTS limit is a conceptual or a practical issue here (i.e., whether the ordinal rule initially only applies within OTS limits, or whether it applies to all cardinals but fails). If it is conceptual, then that would mean children who have difficulty combining OTS and ANS cannot use evidence from higher ordinals in the input for their ordinal rule.

However, evidence from higher ordinals would not be strictly necessary for Dutch children. Following Yang (2016) as discussed above, two ordinals suffice to offset the single exception (or even two exceptions, if eerste 'first' must be considered an ordinal). Children can thus use the two regular ordinals as evidence for their rule, and generalize over these examples before actually understanding the meanings of the whole. Again, this goes against the claim in Clark (2014), that when it comes to derivational morphology, children learn individual (complex) forms lexically at first, and only form a productive rule after sufficient examples of such a rule are stored.

Finally, the fact that the other 'exception' to the rule is acquired early is no surprise: for superlative eerste 'first' (cf. Barbiers 2007) access to the cardinal root is irrelevant and determining the first in line is procedurally less complex (no counting). Something similar holds for laatste 'last' and middelste 'lit: middle-st', for which performance was similarly good (Figure 4): again neither counting, ordinal morphology, nor set size is relevant for these trials. This makes them more like the stative locative PP's vooraan/achteraan 'at the front/at the back' we incorporated as practice items, and with which children experienced very little to no difficulty. Hence, it is also no surprise that in het midden 'in the middle', an analytic alternative to middelste, is unproblematic. Further research would need to explore when stative locative expressions are acquired.

Returning to the main focus of this paper, i.e., ordinal acquisition, the question now is to what extent a rule-based approach to ordinal acquisition holds for English, since the evidence for the ordinal formation rule is more scarce in the English situation, especially within lower ordinals (the domain of the Object Tracking System). This may make the lexical approach more attractive to the learner and/or influence the timing of English ordinal learning, which would yield a different acquisition pathway for English than for Dutch.

\section{Study 2: English comprehension}

\subsection{Method}

The English version of the task was designed to match the Dutch version as closely as possible, but was modified to better match the nature of the English ordinal list and shortened such that the task could be completed in two shorter sessions lasting a maximum of 20 minutes each. We therefore excluded indefinite trials, which were present in the Dutch task, as well as ungrammatical yet regularized stimuli. We included cardinals, synthetic ordinals, and analytic ordinals for the first seven numerals of the count list, plus the superlative last, which were all tested three times each. The total task consisted of 66 trials, two practice items before each session, and the counting routine at the end of each session. The task was procedurally identical to the Dutch version, as were the methods used to assess their cardinal and ordinal knowledge.

A total of 35 children were tested and considered for analysis (15 boys, 20 girls; ages: 39-63 months, $M=51.3, S D=7.0)$. An independent samples t-test indicated that this sample does not significantly differ in age from the Dutch group $(t=1.371(61.54)$, 
$p=0.175$, two-tailed). An additional 5 children were tested but excluded from analysis because they did not complete both sessions of the task. One child was initially included but was the only three-knower in a sample that otherwise (coincidentally) consisted of only CP-knowers. This child (3;06) answered incorrectly on all non-cardinal trials except those for one and last. All children were recruited through the University of Maryland Infant and Child Studies Database or participated at their local preschool. They were reported to be typically-developing and spoke English at home at least $70 \%$ of the time.

\subsection{Results}

We again turned to generalized linear mixed-effects logistic regression models to test the effects of the factors we also discussed for Dutch. As before, we excluded the synthetic and analytic forms for first, as well as the superlative last, and included both synthetic and analytic forms for the six other ordinals in our experiment (second through seventh). We included by-subject random intercepts with slopes for ordinal (place in the count list) as a continuous factor and ordinal type (synthetic, e.g., fourth car, or analytic, e.g., car four) and their interaction, and by-trial random intercepts with slopes for age in months in all models, and the dependent variable in all models was whether a child's response was (in) correct. ${ }^{20}$ This time, knower-level was not included in our analysis because all children included in this sample were classified as a CP-knower. We instead included age in months (continuous), in addition to ordinal (continuous), ordinal type (synthetic, e.g., fourth car, or analytic, e.g., car four) and regularity (irregular, such as second, or regular, such as car two or fourth car) as factors. We centered continuous factors and coded categorical factors with explicit contrasts before analysis. No additional outliers were removed.

As before, we began with a model that included interactions between age on the one hand, and ordinal and regularity on the other, plus their respective main effects. We also added ordinal type and an interaction between type and age. We then compared this model to one in which we replaced ordinal as a continuous factor and regularity by a categorical factor ordinal. However, as we saw with Dutch, treating ordinal as a categorical factor does not lead to an improvement: the AIC and BIC in the more complex model are 998.71 and 1137.5 respectively, while those in the initial, more simple model are 977.01 and 1084.9. We thus retained the original model as described in Table 4.

Table 4: Result summary for correct responses on $2^{\text {nd }}-7^{\text {th }}$ in English: $\beta$ coefficient estimates, confidence intervals, standard errors, associated Wald's z-score and significance level $(p)$ for all predictors in the final analysis. Formula: Response $\sim$ OrdinalContinuous + Regularity + Type + AgeInMonths + OrdinalContinuous: AgelnMonths + Regularity: AgelnMonths + Type: AgeInMonths + $(1+$ OrdinalContinuous*Type|Subject $)+(1+$ AgeinMonths|Trial $)$.

\begin{tabular}{|l|r|c|c|c|c|}
\hline Predictors & Estimate & Cl & SE $\boldsymbol{\beta}$ & $\boldsymbol{Z}$ & $\boldsymbol{p}$ \\
\hline Intercept & -0.049 & $-1.128-1.031$ & 0.551 & -0.088 & 0.9297 \\
\hline Ordinal & -0.212 & $-0387--0.036$ & 0.090 & -2.362 & $\mathbf{0 . 0 1 8 2}$ \\
\hline Regularity & 2.201 & $-0.704-2.804$ & 0.308 & 7.154 & $<\mathbf{0 . 0 0 0 1}$ \\
\hline Type & 0.068 & $-0.578-0.715$ & 0.330 & 0.207 & 0.8357 \\
\hline Age in months & 0.096 & $0.067-0.259$ & 0.083 & 1.158 & 0.2467 \\
\hline Ordinal * Age & 0.007 & $-0.021-0.035$ & 0.014 & 0.498 & 0.6182 \\
\hline Regularity * Age & -0.048 & $-0.151-0.054$ & 0.052 & -0.925 & 0.3548 \\
\hline Type * Age & -0.016 & $-0.122-0.089$ & 0.054 & -0.299 & 0.7647 \\
\hline
\end{tabular}

\footnotetext{
${ }^{20}$ Note that the random effects structure differs from the one used in the analysis of the Dutch data, in which the random slope for the interaction is excluded due to convergence errors. Such errors did not occur here.
} 
The final model only reveals significant main effects of ordinal and regularity, such that higher ordinals are less likely to be comprehended correctly than lower ones, and that regular ordinals are much more likely to elicit a correct response than irregular ones. These effects go in the expected direction. None of the other main or interaction effects are significant: we see no evidence for differences between synthetic (morphological, fourth car type) and analytic (syntactic, car four type) ordinals, beyond those determined by the regular nature of analytic ordinals, and there is no evidence for an effect of age.

Figure 5 depicts the percentage of correct responses per condition in the raw data, providing more concrete insight into children's performance. Note that cardinals, first and last are included here for comparative purposes, though we did not include them in the model.

The cardinal data in Figure 5 show that cardinal performance exceeds ordinal performance on a per-numeral basis, and that performance on certain ordinals (especially higher ones) is not related to performance on their corresponding cardinals. The ordinal data show that performance is mostly consistent: both analytic ordinals and regular synthetic ordinals elicit relatively high scores (all hovering around 60\%), though lower than cardinals, whereas correct responses to irregular (synthetic) ordinals second, third and fifth occur less than half of the time. ${ }^{21}$ The effect of this regularity is supported by children's semi-spontaneous production during the task: analytic forms hardly occurred, but a handful of children would sometimes produce regularized synthetic forms (*oneth, *twoth, *threeth and *five-eth), either during the task or in the counting session at the end. Forms such as *thirdth did not occur. Like Dutch children, they would sometimes ask for clarification or indicate not knowing what to look for on the irregular trials, as the examples in (11) through (14) show. Such utterances did not occur on regular ordinal trials.

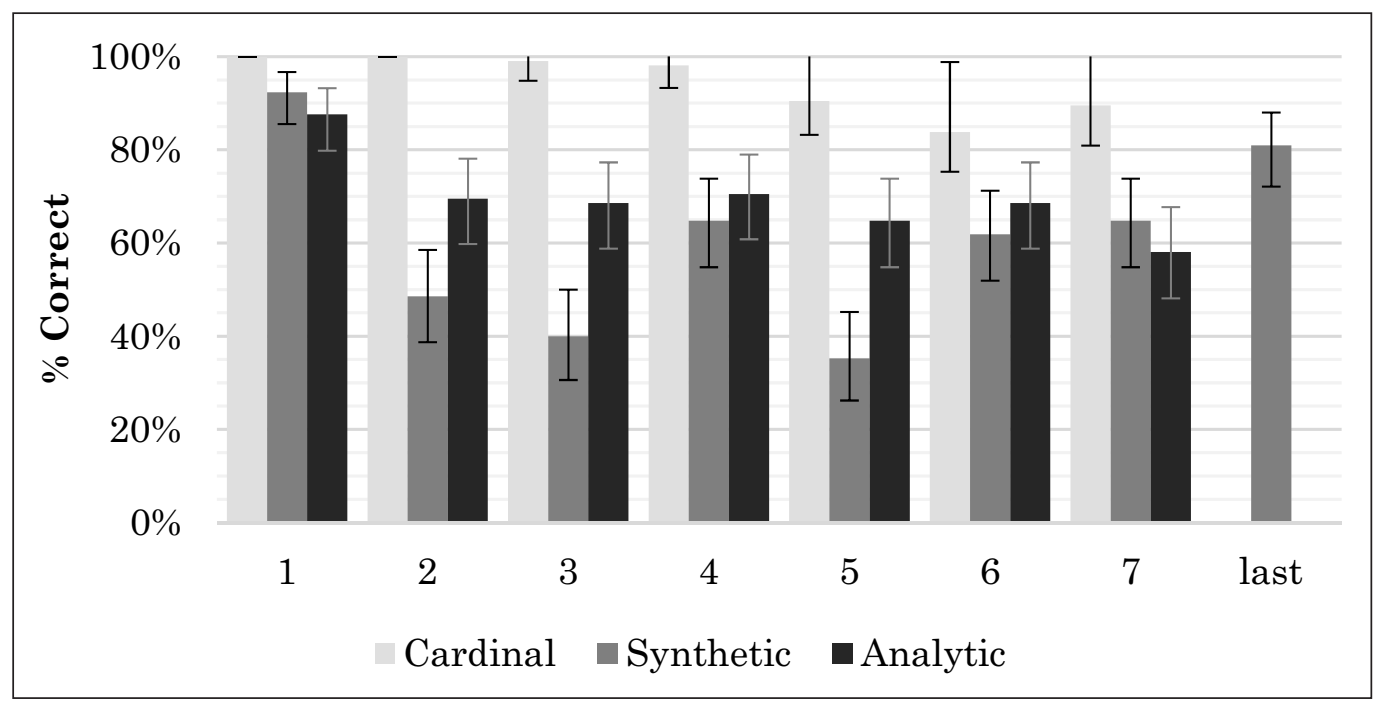

Figure 5: Percentage of correct responses to all tested numeral conditions (cardinals, synthetic ordinals and analytic ordinals) and last in English. Error bars indicate $95 \% \mathrm{Cl}$.

\footnotetext{
${ }^{21}$ A reviewer asked for a more specific analysis looking only at second, third and fifth compared to their analytic counterparts. We ran another model on the subset of the data including only these ordinals, and ran a model identical to the first, minus the factor type and the accompanying interaction with age, as type and regularity are collapsed here. Formula: Response $\sim$ OrdinalContinuous + Regularity + AgeInMonths + OrdinalContinuous: AgeInMonths + Regularity: AgeInMonths + $(1+$ OrdinalContinuous * Regularity|Subject $)+(1+$ AgeinMonths|Trial $)$. Much like before, the only significant factor here is regularity $(\beta=2.466, C I=1.193-3.740, S E=0.650, Z=3.795, p=0.00015)$. There were no significant effects of ordinal $(p=0.07)$, age $(p=0.2815)$, or interactions between age and ordinal $(p=0.4808)$ or age and regularity $(p=0.1329)$.
} 


\section{Is fifth five?}

(12) I don't know which one the second duck is.

Sometimes I don't know what you're saying, like with third.

[Counts to six, was asked for fifth.] I think I passed it.

The figure also shows that the last and first objects in line (regardless of form) elicited the most correct responses: children responded correctly roughly $80 \%$ to $90 \%$ of the time. This is in line with the Dutch data above, and also unsurprising given the data and discussion in Meyer et al. (2018) and the acquisition of superlatives in general.

The figure presents group results. Individual patterns show that some children are more informative than others. Many exhibited consistent performance across the board, making them the least informative here. (Nine responded correctly on at least two out of three trials on each condition, while eight responded incorrectly on all conditions). However, six of the remaining children responded correctly to all regular ordinals, but made more than two errors per condition on all irregular ordinals. An additional two children knew all the regulars and second, one also knew third. Among the remaining ten children, no clear pattern exists for the regular ordinals. Four could find second but not third or fifth; whereas only one child could find third but not the other irregulars, or fifth but not the other irregulars. No children did worse on cardinal than ordinal conditions, no children did worse on analytic forms than synthetic ones, and no children only did well on (any) irregulars.

\subsection{Discussion}

The outcome above should now contain no real surprises, as it points largely in the same direction of the Dutch data, namely towards a rule-based approach to ordinal acquisition. The most telling piece of evidence here is the presence of a significant effect of regularity, in the absence of an effect of type. Analytic forms pose no additional problems to children, despite their different form, slightly different meaning, and lower frequency. Irregular forms, on the other hand, are more difficult than their analytic counterparts and regular neighbors: performance on irregular ordinals second, third, and fifth is lower than e.g., car three and the sixth coat. We take this to be convincing evidence that a transparent relationship between the ordinal and its cardinal base is most important in acquiring ordinals. The few semi-spontaneous occurrences of oneth, twooth, threeth and fiveth supports the idea that children have productive knowledge of the ordinal formation rule. Such overgeneralizations have been noted casually in the literature as well (Pinker 1999, Rumelhart \& Norman 1978).

The data also show that this transparency is not the only factor. The effect of ordinal as a continuous variable suggests that the place in the ordinal count list also plays a small but significant role. This encoding also turned out to be a better way of describing our data than encoding ordinal as a categorical variable. The effects of this factor are not as clearly visible as in the Dutch data above: here, there is no clear drop in performance for higher (regular) ordinals. ${ }^{22}$ Still, the difference between cardinal and ordinal performance suggests that something about ordinals is considerably more trying than cardinals.

Our data reveal no evidence for an effect of age in American English speaking CP-knowers. This is unsurprising given previous work on Dutch, which suggest that any

\footnotetext{
${ }^{22}$ Note that an interaction between regularity and ordinal is not significant and does not improve our model. Hence, this effect of ordinality holds across regular and irregular forms.
} 
age effect seems to be limited to the subset-knower stages and plays a smaller role than knower-level, at least in comprehension (cf. Meyer et al. (2018, under review). This makes it likely that, while of course older children will do better than younger ones eventually, age does not add anything above and beyond other predictors in our model, i.e., the place of the ordinal in the count list and regularity. The lack of interaction effects means this holds for both synthetic and analytic, both regular and irregular and low and high ordinals.

One further observation has to do with the performance within the set of irregular ordinals. If any kind of transparency can help in acquiring ordinals (not just the relationship between the cardinal and the ordinal), then we might have expected fifth to elicit more correct responses: the irregularity here is not a case of suppletion (such as with second), but is phonological, and only involves the vowel (and, depending on the speaker, devoicing or elision of the fricative). ${ }^{23}$ This is less complex than the relationship between three and third, which involves metathesis, a change in the vowel itself, and the suffix. This notwithstanding, performance on fifth is not better than on other irregular ordinals. Perhaps frequency and/or the factor ordinal outweigh any effect of the complexity of the irregularity, or perhaps the kind of irregularity is irrelevant - we leave this for future research to explore.

\section{Comparing Dutch and English}

The models presented for Dutch and English point in the same direction: the main factor of influence is regularity, not ordinal type. However, since the Dutch sample contained children in all of the five knower-level stages, it is hard to compare these results directly. We therefore conducted a third analysis, in which the CP-knowers from both languages are analyzed together. This not only keeps knower-level constant, but also means the groups are more comparable in terms of sample size (Dutch $N=41$, US English $N=35$ ). There was no significant difference in age between the Dutch $(M=53.2, S D=5.1)$ and English $(M=51.3, S D=7.0)$ groups $(t(9.997)=-5.061, p<0.0001)$.

In addition to the factors discussed for other analyses above (ordinal, regularity, type and age), we can now add in the effect of language as an additional fixed factor. Because previous models (in both languages, and in previous studies) did not provide evidence for interaction effects between age and other factors, we left them out of the present model. Instead, we added in interactions between language and the other four fixed factors, to see whether the patterns between the two language groups differed. We included bysubject random intercepts with slopes for ordinal (place in the count list) as a continuous factor and ordinal type (synthetic, e.g., vierde auto 'fourth car', or analytic, e.g., auto vier 'car four') and their interaction (as for the English analysis in section 6.2, but not the Dutch analysis in 5.2), and by-trial random intercepts with slopes for age (in months) and language. Table 5 describes the outcome of this model.

The model reveals significant effects of ordinal, regularity, language, and age. None of the interactions are found to be significant, though the interaction between regularity

\footnotetext{
$\overline{{ }^{23} \text { One might even }}$ argue that the alternation between /ai/ and /I/ is a more general pattern found elsewhere in English, which might help children recognize the relationship between the cardinal and the ordinal. However, this alternation does not seem to correspond to a clear domain, word class, or semantic relationship; perhaps the most accessible case (besides the irregular plural of child, children) pertains to tense (e.g., write-written, hide-hid), but examples also include deverbal nouns (crime-criminal, decide-decision, divine-divinity) and adjectives (apply-applicable, divide-divisible), and derived nominals (e.g., wise-wisdom, wide-width, rite-ritual). The majority of these examples are unlikely to occur in child-directed speech. Even if the data were abundant in the input, the question remains whether this would lead to a broad phonological generalization. Children may be able to formulate a rule linked to tense, but our data suggest children cannot readily apply this rule outside the domain for which it was initially conceived.
} 
and language trends towards significance, such that the effect of regularity is greater for English-speaking CP-knowers (see also Figure 6). ${ }^{24}$

Effects of ordinal and regularity are of no surprise at this point, nor is the lack of an effect of ordinal type: for both languages, we saw that higher ordinals yielded lower comprehension scores than lower ones, as did irregular forms compared to regular ones, and that children do not experience greater difficulty with car four type (analytic) ordinals over fourth car type (synthetic) ones. Again, we take this all to point in the direction of rule-based learning, with only a small part of the pattern related to age. The main purpose of this extra model, however, was to examine any effects of language. These effects turn out to be significant: the English learners are less likely to provide a correct response than Dutch learners.

Figure 6 shows the mean percentage of correct responses to Dutch and English ordinals, grouped by the (ir)regularity of the tested ordinal. (See Sections 5.2 and 6.2 for individual

Table 5: Result summary for correct responses on ordinals in Dutch and English CP-knowers: $\beta$ coefficient estimates, confidence intervals, standard errors, associated Wald's $z$-score and significance level $(p)$ for all predictors. Formula: Response (OrdinalContinuous + Regularity)* Language + Type + AgelnMonths + Type:Language + AgelnMonths:Language + $(1+$ OrdinalContinuous*Type $\mid$ Subject $)+(1+$ AgelnMonths + Language|Trial) .

\begin{tabular}{|l|r|c|c|c|c|}
\hline Predictors & Estimate & \multicolumn{1}{|c|}{ Cl } & SE $\boldsymbol{\beta}$ & \multicolumn{1}{|c|}{$\boldsymbol{~}$} & \multicolumn{1}{c|}{$\boldsymbol{p}$} \\
\hline Intercept & 0.787 & $0.069-1.505$ & 0.366 & 2.149 & 0.0316 \\
\hline Ordinal & -0.303 & $-0.410-0.196$ & 0.055 & -5.531 & $<\mathbf{0 . 0 0 0 1}$ \\
\hline Regularity & 1.833 & $1.368-2.298$ & 0.237 & 7.728 & $<\mathbf{0 . 0 0 0 1}$ \\
\hline Language & -1.755 & $-3.187--0.324$ & 0.731 & -2.403 & $\mathbf{0 . 0 1 6 3}$ \\
\hline Type & -0.347 & $-0.845-0.153$ & 0.255 & -1.361 & 0.1735 \\
\hline Age in months & 0.121 & $0.005-0.238$ & 0.059 & 2.047 & $\mathbf{0 . 0 4 0 6}$ \\
\hline Ordinal * Language & 0.153 & $-0.060-0.366$ & 0.109 & 1.41 & 0.1585 \\
\hline Regularity * Language & 0.833 & $-0.070-1.737$ & 0.461 & 1.807 & 0.0707 \\
\hline Language * Type & 0.554 & $-0.44-1.549$ & 0.508 & 1.09 & 0.2758 \\
\hline Language * Age & -0.094 & $-0.322-0.134$ & 0.116 & -0.805 & 0.4211 \\
\hline
\end{tabular}

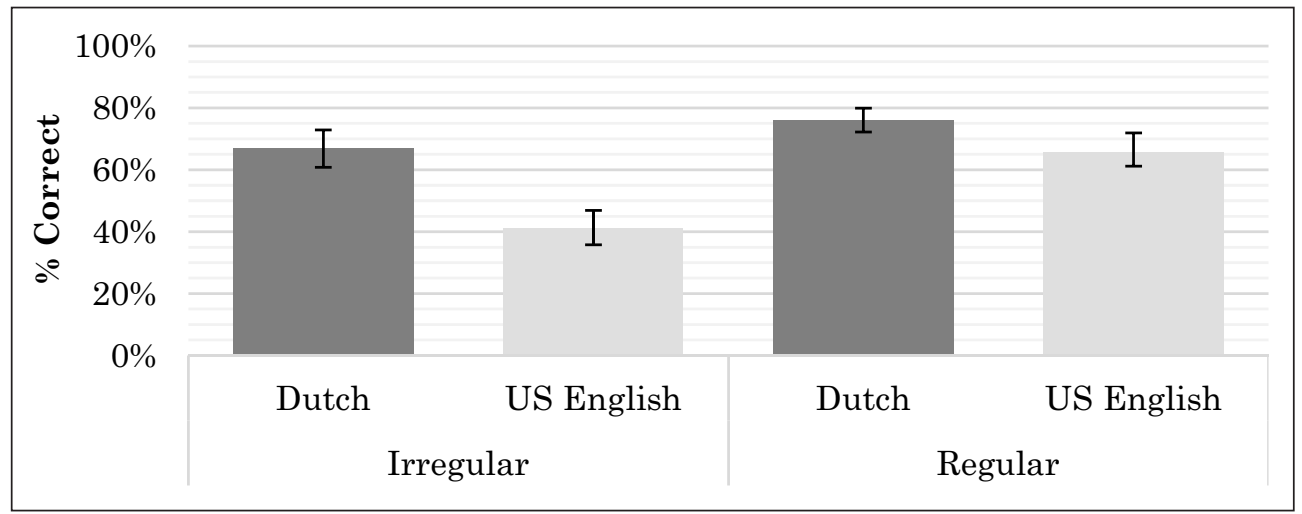

Figure 6: Mean percentage of correct responses on all definite ordinals tested, for irregular and regular ordinals for both Dutch and English CP-knowers. Error bars indicate $95 \% \mathrm{Cl}$.

\footnotetext{
${ }^{24}$ A reviewer points out that our comparison may have had a different outcome if we had considered a different definition of regularity, e.g., had coded fifth or achtste as regular. While this is true, the descriptive data in Figure 5 and the outcome described for Dutch in section 5 lead us to believe the distinction we hypothesized suits the present purposes and that a different categorization would not be more valid or informative.
} 
ordinal results per language.) While Dutch children outperform the English learners when it comes to regular ordinals, the clear difference is in the irregular domain: Dutch CP-knowers provide more correct responses to derde 'third' than English learners to second, third, and fifth combined. English does have more irregular ordinals than Dutch, and so English learners are presented with a greater challenge as they have more exceptions to acquire. It also means they have less evidence for the regular forms, which we think leads to a marginal general delay in ordinal acquisition. Ultimately, however, having less evidence for the rule does not impact their ability to acquire the rule, only the amount of time they need to do so. The English group shows that they have sufficient evidence for a productive ordinal formation rule, and that, as in Dutch, a rule-based acquisition pattern is favored over lexical learning.

\section{Conclusion}

The data from our two 'Give Me'-type comprehension experiments are clearly in line with the idea put forward in Meyer et al. (2018): regularity is key. As long as the relationship between an ordinal and its cardinal base is transparent, children are able to derive the meaning of the ordinal, regardless of whether the ordinal is ungrammatical and absent from the input (as with *driede 'threeth'), and regardless of whether it is formed syntactically (as with analytic ordinals such as auto drie 'car three') or morphologically (as with the more naturally occurring vierde auto 'fourth car'). Though the ordinals that we considered irregular here differ with regard to what makes them irregular (second, third, fifth and derde 'third' are all 'irregular' in a different way), for the learner this does not seem to matter much: the cardinal root must remain untouched. We leave effects of irregularity type to be explored in future work.

The generalization above not only holds for learners of Dutch, a language with a relatively regular ordinal count list, but also for learners of English, which has a much less regular ordinal list and thus provides less evidence for the ordinal rule. However, the pattern they exhibit differs: while Dutch learners show a clear effect of 'low' ordinals $(\leq 4)$ and 'high' ones $(\geq 6)$, the effect of place in the ordinal list is more gradual in English. We suggest this difference between Dutch and English is caused by what cognitive processes play a role and what evidence is needed. For lower ordinals in Dutch, children have sufficient evidence for the ordinal rule within the OTS domain. For higher ordinals, ANS and OTS must be co-activated. This extra component adds to the cognitive load, which prevents successful application of the rule until that added difficulty is overcome. (Alternatively, the learner may initially think the rule applies only to low ordinals, failing to process evidence from high ordinals as evidence for the same rule.) The data in Meyer et al. (under review) suggest this happens by age 5, some six months after Dutch children typically become CP-knowers.

This difference does not appear in English because there is insufficient evidence for a rule within the OTS domain: fourth conforms to a rule that the learner can only postulate if he has collected evidence from higher ordinals such as sixth and seventh. Put differently, merging OTS and ANS is necessary for English learners to comprehend any ordinals. This may require a longer learning trajectory. Though the English learners in our sample were the same age as the Dutch children we tested, the literature would suggest they have been CP-knowers for longer, allowing them more time to actively train their 'number muscle', while they collect the relatively scarce evidence needed for the ordinal rule. Note that the rule-based approach is nonetheless the more efficient option. If it were not, we would have expected earlier acquisition of the most frequent forms (e.g., second). A lexicalist approach cannot account for the difficulties with irregular forms, the relative ease of analytic forms, or the individual responses described above - neither for the Dutch, nor for 
the English data. Instead, it seems that regularity, or at least a transparent relationship between the cardinal and the root, is key.

These findings therefore support the main hypothesis under investigation in this paper, in line with as well as elaborating on the work in Meyer et al. (2018) that inspired this study. These results are nonetheless somewhat surprising, as they mean that ordinal acquisition is unlike acquisition patterns typically described for the acquisition of derivation (as discussed above, in Meyer 2019, and Clark 2014) or inflection (see Meyer 2019). However, as Clark (2014) notes, the acquisition of derivation relies on children's ability to identify the components of complex words, the semantic transparency of the affix and frequency. Ordinals may not be frequent, but their formation is reliable and transparent; the rule is productive in a machine-like fashion for any cardinal root. And cardinals, being somewhere between adjectives and nouns (Corbett 1978), are something of a linguistic outcast in themselves. Given that they stand out, and are notoriously cumbersome to learn, perhaps we should not be surprised if children are alerted to cardinals and are eager to recycle numerical knowledge they already worked so hard to acquire the first time. The contribution of the ordinal affix is relatively easy once the meaning of the cardinal is clear, and so linguistically the (regular) ordinal is no challenge. The real hurdle is getting the underlying concepts in place and maintaining the integration between two abstract systems of number (OTS and ANS); the morphological irregularities follow soon enough.

\section{Glossing Abbreviations}

$\mathrm{PL}=$ plural

$\mathrm{SG}=$ singular

\section{Acknowledgements}

We would like to thank the children and schools that participated in this study. Many thanks also go to the members of the Maryland Cognitive Neuroscience of Language Lab and the Project on Children's Language Learning for valuable feedback and for making the cross-linguistic part of the study possible, especially Jeffrey Lidz, Juliana Gerard and Tara Mease. This paper also benefited from discussion with various conferences audience and ACLC members, most notably Suzanne Aalberse.

\section{Funding Information}

This project was funded by the Netherlands Organization for Scientific Research (NWO) as part of the Horizon program Knowledge and Culture (grant 317-70-014).

\section{Competing Interests}

The authors have no competing interests to declare.

\section{References}

Almoammer, Alhanouf, Jessica Sullivan, Chris Donlan, Franc Marušič, Rok Žaucer, Timothy O'Donnell \& David Barner. 2013. Grammatical morphology as a source of early number word meanings. Proceedings of the National Academy of Sciences 110. 18448-18453. DOI: https://doi.org/10.1073/pnas.1313652110

Anderson, Stephen Robert. 1969. West Scandinavian vowel systems and the ordering of phonological rules. Cambridge, MA: MIT PhD dissertation.

Barbiers, Sjef. 2007. Indefinite numerals one and many and the cause of ordinal suppletion. Lingua 117. 859-880. DOI: https://doi.org/10.1016/j.lingua.2006.03.003

Barner, David, Amanda Libenson, Pierina Cheung \& Mayu Takasaki. 2009. Cross-linguistic relations between quantifiers and numerals in language acquisition: Evidence from 
Japanese. Journal of Experimental Child Psychology 103. 421-440. DOI: https://doi. org/10.1016/j.jecp.2008.12.001

Bates, Douglas, Martin Maechler, Ben Bolker \& Steve Walker. 2015. Fitting linear mixedeffects models using lme4. Journal of Statistical Software 67(1). 1-48. DOI: https://doi. org/10.18637/jss.v067.i01

Blom, Elma \& Siebe de Korte. 2008. De verwerving van het Nederlands: Dummies en Verb Second. [The acquisition of Dutch: Dummies and Verb Second.] Nederlandse Taalkunde 13(2). 133-159.

Clark, Eve V. 2014. Acquisition of derivational morphology. In Rochelle Lieber \& Pavel Štekauer (eds.), The Oxford handbook of derivational morphology, 1-21. Oxford: Oxford University Press.

Colomé, Àngels \& Marie-Pascale Noël. 2012. One first? Acquisition of the cardinal and ordinal uses of numbers in preschoolers. Journal of Experimental Child Psychology 133. 233-247. DOI: https://doi.org/10.1016/j.jecp.2012.03.005

Condry, Kirsten F. \& Elizabeth S. Spelke. 2008. The development of language and abstract concepts: The case of natural number. Journal of Experimental Psychology 137. 22-38. DOI: https://doi.org/10.1037/0096-3445.137.1.22

Corbett, Greville G. 1978. Universals in the syntax of cardinal numerals. Lingua 46(4). 355-368. DOI: https://doi.org/10.1016/0024-3841(78)90042-6

Davies, Mark. 2008-. The Corpus of Contemporary American English (COCA): 520 million words, 1990-present. Available online at http://corpus.byu.edu/coca/.

De Belder, Marijke. 2007. Silence and the construct state in Dutch date expressions. In Bettelou Los and Marjo van Koppen (eds.), Linguistics in the Netherlands 24. 25-35. DOI: https://doi.org/10.1075/avt.24.05de

De Belder, Marijke. 2009. On the syntax of titles. Paper presented at The 17th Conference of Student Organization of Linguistics in Europe (ConSOLE XVII), Nova Gorica, January 16-18, 2009.

Dehaene, Stanislas \& Jacques Mehler 1992. Cross-linguistic regularities in the frequency of number words. Cognition 43. 1-29. DOI: https://doi.org/10.1016/0010-0277(92) 90030-L

Fischer, Florence E. \& Robert D. Beckey. 1990. Beginning kindergartners perception of number. Perceptual and Motor Skills 70. 419-425. DOI: https://doi.org/10.2466/pms. 1990.70.2.419

Geary, David C. \& Alex M. Moore. 2016. Cognitive and brain systems underlying early mathematical development. Progress in Brain Research 227. 75-103. DOI: https://doi. org/10.1016/bs.pbr.2016.03.008

Gelman, Rochel \& Charles Randy Gallistel. 1978. The child's understanding of number. Cambridge, MA: Harvard University Press. (Second edition: 1986.)

Hamburger, Henry \& Stephen Crain. 1984. Acquisition of cognitive compiling. Cognition 17. 85-136. DOI: https://doi.org/10.1016/0010-0277(84)90015-5

Huang, Yi Ting, Elizabeth S. Spelke \& Jesse Snedeker. 2010. When is four far more than three? Children's generalization of newly acquired number words. Psychological Science 21. 600-606. DOI: https://doi.org/10.1177/0956797610363552

Hurford, James. 1987. Language and number. The emergence of a cognitive system. Oxford: Basil Blackwell.

Kiparsky, Paul. 1973. Elsewhere in phonology. In Stephen Robert Anderson \& Paul Kiparsky (eds.), A festschrift for Morris Halle, 93-106. New York: Holt, Rinehart and Winston.

Le Corre, Mathieu, Gretchen Van de Walle, Elizabeth M. Brannon \& Susan Carey. 2006. Re-visiting the competence/performance debate in the acquisition of counting as a 
representation of the positive integers. Cognitive Psychology 52. 130-169. DOI: https:// doi.org/10.1016/j.cogpsych.2005.07.002

Le Corre, Mathieu, Peggy Li, Becky H. Huang, Gisela Jia \& Susan Carey. 2016. Numerical syntax supports number word learning: Evidence from a comparison of young Mandarin and English learners. Cognitive Psychology 88. 162-186. DOI: https://doi.org/10.1016/j. cogpsych.2016.06.003

Le Corre, Mathieu \& Susan Carey. 2007. One, two, three, four, nothing more: An investigation of the conceptual sources of the verbal counting principles. Cognition 105. 395-438. DOI: https://doi.org/10.1016/j.cognition.2006.10.005

Lee, Michael \& Barbara Sarnecka. 2010a. A model of knower-level behavior in number concept development. Cognitive Science 34(1). 51-67. DOI: https://doi.org/10. 1111/j.1551-6709.2009.01063.x

Lee, Michael \& Barbara Sarnecka. 2010b. Number-knower levels in young children: insights from Bayesian modeling. Cognition 120(3). 391-402. DOI: https://doi.org/10.1016/j. cognition.2010.10.003

Lyons, Ian M., Stephen E. Vogel \& Daniel Ansari. 2016. On the ordinality of numbers: A review of neural and behavioral studies. Progress in Brain Research 227. 187-221. DOI: https://doi.org/10.1016/bs.pbr.2016.04.010

Marcus, Gary P., Steven Pinker, Michael Ullman, Michelle Hollander, T. John Rosen \& Fei Xu. 1992. Overregularization in language acquisition. Monographs of the Society for Research in Child Development 57(4). 1-78. DOI: https://doi.org/10.2307/1166115

Matthei, Edward. 1982. The acquisition of prenominal modifier sequences. Cognition 11. 301-332. DOI: https://doi.org/10.1016/0010-0277(82)90018-X

Meyer, Caitlin. 2019. Rule and order: acquiring ordinals in Dutch and English. PhD Dissertation, University of Amsterdam. Utrecht: LOT Publications.

Meyer, Caitlin, Sjef Barbiers \& Fred Weerman. 2016. Order and ordinality: the acquisition of cardinals and ordinals in Dutch. In Jennifer Scott \& Deb Waughtal (eds.), Proceedings of the 40th annual Boston University Conference on Language Development, 253-266. Somerville, MA: Cascadilla Press.

Meyer, Caitlin, Sjef Barbiers \& Fred Weerman. 2018. Ordinals are not as easy as one, two, three: the acquisition of cardinals and ordinals in Dutch. Language Acquisition. DOI: https://doi.org/10.1080/10489223.2017.1391266

Meyer, Caitlin, Sjef Barbiers \& Fred Weerman. Under review. Rules rule in Dutch L1 ordinal comprehension and production. Ms. University of Amsterdam, Leiden University.

Miller, Kevin F., Susan M. Major, Hua Shu \& Houcan Zhang. 2000. Ordinal knowledge: Number names and number concepts in Chinese and English. Canadian Journal of Experimental Psychology 54(2). 129-139. DOI: https://doi.org/10.1037/h0087335

Negen, James \& Barbara W. Sarnecka 2012. Number-concept acquisition and general vocabulary development. Child Development 83(6). 2019-2027. DOI: https://doi.org/ 10.1111/j.1467-8624.2012.01815.x

Negen, James, Barbara W. Sarnecka \& Michael D. Lee. 2012. An Excel sheet for inferring children's number-knower levels from give- $N$ data. Behavior Research Methods 44(1). 57-66. DOI: https://doi.org/10.3758/s13428-011-0134-4

Oostdijk, Nelleke. 2000. Het corpus gesproken Nederlands. [The spoken Dutch corpus.] Nederlandse Taalkunde 5(3). 280-284.

Piantadosi, Steven T., Julian Jara-Ettinger \& Edward Gibson. 2014. Children's learning of number words in an indigenous farming-foraging group. Developmental Science 17(4). 553-563. DOI: https://doi.org/10.1111/desc.12078

Pinker, Steven. 1999. Words and rules. New York, NY: Harper Perennial. 
R Core Team. 2016. A language and environment for statistical computing. R Foundation for Statistical Computing, Vienna, Austria. http://www.R-project.org/.

Rumelhart, David E. \& Donald A. Norman. 1978. Accretion, tuning and restructuring: Three modes of learning. In John W. Cotton \& Roberta L. Klatzky (eds.), Semantic factors in cognition, 37-53. Hillsdale, NJ: Erlbaum.

Sarnecka, Barbara W. 2015. Learning to represent exact numbers. Synthese. 1-18. DOI: https://doi.org/10.1007/s11229-015-0854-6

Sarnecka, Barbara W., Valentina G. Kamenskaya, Yuko Yamana, Tamiko Ogura \& Yulia Yudovina. 2007. From grammatical number to exact numbers: Early meanings of one, two, and three in English, Russian and Japanese. Cognitive Psychology 55(2). 136-168. DOI: https://doi.org/10.1016/j.cogpsych.2006.09.001

Siloni, Tal. 1994. Noun phrases and nominalizations. Geneva: University of Geneva PhD dissertation.

Sleeman, Petra \& Aafke Hulk. 2013. L1 acquisition of noun ellipsis in French and Dutch: Consequences for linguistic theory. In Sergio Baauw, Frank Drijkoningen, Luisa Meroni \& Manuela Pinto (eds.), Romance languages and linguistic theory, 249-266. Amsterdam: John Benjamins. DOI: https://doi.org/10.1075/rllt.5.12sle

Syrett, Kristen. 2016. Acquisition of comparatives and degree constructions. In Jeffrey Lidz, William Snyder \& Joe Pater (eds.), The Oxford handbook of developmental linguistics. Oxford: Oxford University Press. DOI: https://doi.org/10.1093/oxfordhb/978019960 1264.013.20

Trabandt, Corinna, Alexander Thiel, Emanuela Sanfelici \& Petra Schulz. 2015. On the acquisition of ordinal numbers in German. In Esther Ruigendijk \& Cornelia Hamann (eds.), Proceedings of GALA 2013, 521-532. Cambridge, MA: Cambridge Scholar Publishing.

Wynn, Karen. 1992. Children's acquisition of the number words and the counting system. Cognitive Psychology 24. 220-251. DOI: https://doi.org/10.1016/0010-0285(92)90008-P

Yang, Charles. 2016. The price of linguistic productivity. How children learn to break the rules of language. Cambridge, MA: MIT Press. DOI: https://doi.org/10.7551/mitpress/ 9780262035323.001.0001

Zuckerman, Shalom. 2001. The acquisition of "optional" movement. PhD Dissertation, University of Groningen. Groningen: Groningen Dissertations in Linguistics (GRODIL).

How to cite this article: Meyer, Caitlin, Sjef Barbiers and Fred Weerman. 2020. Many systems, one strategy: Acquiring ordinals in Dutch and English. Glossa: a journal of general linguistics 5(1): 100.1-31. DOI: https://doi.org/10.5334/ gjgl.595

Submitted: 19 December 2017 Accepted: 02 January 2020 Published: 12 October 2020

Copyright: $\odot 2020$ The Author(s). This is an open-access article distributed under the terms of the Creative Commons Attribution 4.0 International License (CC-BY 4.0), which permits unrestricted use, distribution, and reproduction in any medium, provided the original author and source are credited. See http://creativecommons.org/licenses/by/4.0/.

Glossa: a journal of general linguistics is a peer-reviewed open access journal

] $\mathrm{u}[\quad$ published by Ubiquity Press.

OPEN ACCESS $\boldsymbol{\varnothing}$ 